\title{
Tuberous Sclerosis Complex Activity Is Required to Control Neuronal Stress Responses in an mTOR-Dependent Manner
}

\author{
Alessia Di Nardo, ${ }^{1}$ Ioannis Kramvis, ${ }^{1}$ Namjik Cho, ${ }^{1}$ Abbey Sadowski, ${ }^{1}$ Lynsey Meikle, ${ }^{2}$ David J. Kwiatkowski, ${ }^{2}$ and \\ Mustafa Sahin ${ }^{1}$ \\ ${ }^{1}$ The F. M. Kirby Neurobiology Center, Department of Neurology, Children's Hospital Boston, Harvard Medical School, Boston, Massachusetts 02115, and \\ ${ }^{2}$ Division of Translational Medicine, Department of Medicine, Brigham and Women's Hospital, Harvard Medical School, Boston, Massachusetts 02115
}

\begin{abstract}
Tuberous sclerosis complex (TSC) is a neurogenetic disorder caused by loss-of-function mutations in either the TSC1 or TSC2 genes and frequently results in prominent CNS manifestations, including epilepsy, mental retardation, and autism spectrum disorder. The TSC1/ TSC2 protein complex plays a major role in controlling the Ser/Thr kinase mammalian target of rapamycin (mTOR), which is a master regulator of protein synthesis and cell growth. In this study, we show that endoplasmic reticulum (ER) stress regulates TSC1/TSC2 complex to limit mTOR activity. In addition, Tsc2-deficient rat hippocampal neurons and brain lysates from a Tsc1-deficient mouse model demonstrate both elevated ER and oxidative stress. In Tsc2-deficient neurons, the expression of stress markers such as $\mathrm{CHOP}$ and HO-1 is increased, and this increase is completely reversed by the mTOR inhibitor rapamycin both in vitro and in vivo. Neurons lacking a functional TSC1/TSC2 complex have increased vulnerability to ER stress-induced cell death via the activation of the mitochondrial death pathway. Importantly, knockdown of $\mathrm{CHOP}$ reduces oxidative stress and apoptosis in Tsc2-deficient neurons. These observations indicate that ER stress modulates mTOR activity through the TSC protein complex and that ER stress is elevated in cells lacking this complex. They also suggest that some of the neuronal dysfunction and neurocognitive deficits seen in TSC patients may be attributable to ER and oxidative stress and therefore potentially responsive to agents moderating these pathways.
\end{abstract}

\section{Introduction}

Tuberous sclerosis complex (TSC) is an autosomal dominant disorder characterized by the growth of benign tumors called hamartomas in multiple organs, including the brain (Crino et al., 2006). TSC patients suffer from epilepsy, autism, and developmental delay. Within the CNS, TSC is associated with cortical tubers, made up of giant cells, dysmorphic neurons, and astrocytes. TSC is caused by mutations in either the TSC1 or TSC2 genes. Proteins encoded by TSC1 or TSC2 genes interact with each other to form the TSC1/TSC2 complex. One of the major cellular functions of the TSC1/TSC2 complex is to limit protein synthesis and regulate cell size by inhibiting the Rheb-mammalian target of rapamycin (mTOR) pathway (Kwiatkowski and Manning, 2005). Mutations in either TSC1 or TSC2 lead to constitutive activation of mTOR, which phosphorylates substrates such as S6 kinase (S6K) and 4E-BP1, ultimately increasing protein synthesis.

Recently, embryonic fibroblasts and kidney tumors from

Received Feb. 15, 2009; revised March 30, 2009; accepted April 3, 2009.

This work was supported by National Institutes of Health Grants R01 NS058956 (M.S.) and P01 NS024279 (D.J.K.), the Hearst Fund (A.D.), the Manton Foundation and the Children's Hospital Boston Translational Research Program (M.S.), and the Tuberous Sclerosis Alliance (L.M. and M.S.). We thank Paul Rosenberg, Zhigang He, and members of the Sahin laboratory for critical reading of this manuscript, Gokhan Hotamisligil, Umut Ozcan, and Brendan Manning for helpful discussions, Elizabeth Boush and Karin Hoffmeister for help with FACS analysis, and Lihong Bu and the Children's Hospital Boston Mental Retardation and Developmental Disabilities Research Center for technical assistance (supported by National Institutes of Health Grant P01HD18655).

Correspondence should be addressed to Dr. Mustafa Sahin, Department of Neurology, Children's Hospital, Boston, 300 Longwood Avenue, CLSB 13074, Boston, MA 02115. E-mail: mustafa.sahin@childrens.harvard.edu.

DOI:10.1523/JNEUROSCI.0778-09.2009

Copyright $\odot 2009$ Society for Neuroscience $\quad$ 0270-6474/09/295926-12\$15.00/0
Tsc2-deficient mice were shown to have increased endoplasmic reticulum (ER) stress (Ozcan et al., 2008). ER stress can be caused by excessive protein synthesis, perturbation in calcium homeostasis, or nutrient deprivation (Ron and Walter, 2007). Under normal conditions, the ER stress sensor GRP78 has an inhibitory role on the effectors [PKR-like ER kinase (PERK), activating transcription factor 6 (ATF6), and inositol requiring enzyme 1 (IRE1)] of the unfolded protein response (UPR), which is the cellular response to ER stress (Dorner et al., 1992; Liu et al., 2000). During ER overload, GRP78 releases its inhibition of PERK, ATF6, and IRE1 (Mori, 2000) and activates the UPR. The UPR leads to three distinct specific cascades: (1) the PERK/eIF2 $\alpha$ pathway reduces protein synthesis by inhibiting translation; (2) the ATF6 pathway activates transcription of chaperone proteins increasing folding capacity; (3) the IRE/XBP-1 pathway promotes proteosome-dependent protein degradation to remove proteins from the ER (Bertolotti et al., 2000; Mori, 2000; Liu et al., 2003; Rutkowski and Kaufman, 2004). Ultimately, the UPR response results in either the successful elimination of ER overload or, if unsuccessful, in ER stress-induced cell death via caspase activation and induction of the proapoptotic transcription factor CHOP (C/EBP homologous protein, GADD153) (Oyadomari and Mori, 2004).

Although ER stress has been demonstrated in Tsc-deficient mouse embryonic fibroblasts (MEFs) and kidney tumors (Ozcan et al., 2008), it remains unclear whether TSC deficiency leads to ER stress in neurons, what role mTOR pathway plays in neuronal stress response, and whether similar dysfunctions are present in seizure models of Tsc in vivo. To address these questions, we 
investigated the role of the TSC1/TSC2 complex during ER stress in greater detail and examined the effects of TSC deficiency on neuronal stress pathways. We demonstrate that TSC2 is initially inactivated in neurons during ER stress and later activated, as part of an apparent regulatory mechanism to limit mTOR activity. Lack of a functional TSC1/TSC2 complex abolishes this regulation, resulting in increased ER stress and vulnerability to neuronal damage. Furthermore, Tsc-deficient neurons have increased accumulation of reactive oxygen species (ROS) and oxidative stress. Similar dysfunctions were identified in TSC brain lesions in vivo, identifying a new role for the TSC1/TSC2 complex in the neuronal stress response.

\section{Materials and Methods}

Animals. All experimental procedures were performed in compliance with animal protocols approved by the Institutional Animal Care and Use Committee at Children's Hospital (Boston, MA). The Tsc1 ${ }^{c /-} S y n-$ $\mathrm{Cre}^{+}$mice used in this study were described previously (Meikle et al., 2007). For rapamycin treatment, mice were injected intraperitoneally at $6 \mathrm{mg} / \mathrm{kg}$ every other day from postnatal day 9 (P9) to P33. Mice subjected to the On/Off treatment were on rapamycin treatment $(6 \mathrm{mg} / \mathrm{kg})$ every other day from P9 to P30, followed by no treatment until P45 (On/Off) (Meikle et al., 2008).

Neuronal cultures. Neuronal cultures were prepared as published previously (Sahin et al., 2005). Briefly, hippocampi from 18-d-old rat embryos (CD1; Charles River) were isolated under the microscope and collected in HBSS containing $10 \mathrm{~mm} \mathrm{MgCl}_{2}, 1 \mathrm{~mm}$ kynurenic acid, $10 \mathrm{~mm}$ HEPES, and penicillin/streptomycin. After $5 \mathrm{~min}$ dissociation at $37^{\circ} \mathrm{C}$ in $30 \mathrm{U} / \mathrm{ml}$ papain (Worthington), neurons were mechanically triturated and plated in Neurobasal (NB) medium containing B27 supplement, 2 $\mathrm{mm}$ L-glutamine, and penicillin/streptomycin (Invitrogen). For biochemical analysis, cells were plated at $1 \times 10^{6}$ cells per well onto six-well plates coated with $20 \mu \mathrm{g} / \mathrm{ml}$ poly-D-lysine (PDL) and $2.5 \times 10^{6}$ cells per plate for immunofluorescent (IF) studies onto PDL-laminin-coated glass coverslips in 24-well plates.

Lentivirus infection. Viral stocks for lentiviral infection were prepared as described previously (Mostoslavsky et al., 2005), except that the four packaging vectors (kindly provided by Dr. R. C. Mulligan, Department of Genetics, Harvard Medical School, Boston, MA) were cotransfected into HEK293 T cells with the plasmid to be coexpressed using Lipofectamine 2000 according to the instructions of the manufacturer. Viral particles were collected 48 and $72 \mathrm{~h}$ after transfection and filtered though a 0.45 $\mu \mathrm{m}$ membrane. Hippocampal neurons were infected at 1 day in vitro (1 DIV) in the presence of polybrene at $0.6 \mu \mathrm{g} / \mathrm{ml}$. Six hours after infection, the virus-containing medium was replaced by fresh NB/B27 medium. After infection, neurons were kept in culture for an additional $10 \mathrm{~d}$. Control short hairpin RNA (ShRNA) construct against the luciferase gene (here referred as GL3-Sh) was described previously (Flavell et al., 2006). The sequence for $T s c 2$ gene targeting was the following: 5'-GGTGAAGAGAGCCGTATCACA-3'.

Semiquantitative and real-time quantitative PCR. Total RNA was prepared with an RNAeasy kit (Qiagen) following the instructions of the manufacturer and quantified by a spectrophotometer. A total of $2 \mu \mathrm{g}$ of poly(A) mRNA was used for reverse transcription using the SuperScript RT system (Invitrogen). Semiquantitative PCR reactions were performed using Taq Polymerase (PerkinElmer Life and Analytical Sciences). Quantification of the semiquantitative PCR was performed by densitometry scans, and values were normalized against total $\beta$-actin. Real-time PCRs were performed using SYBG Green PCR Master Mix (Applied Biosystems). All quantitative PCR (qPCR) reactions were performed in triplicate and normalized against glyceraldehyde-3-phosphate dehydrogenase (GAPDH). Analysis was performed using 7300 System SDS Software on a 7300 Real Time PCR System. The sequences of the primers for both semiquantitative and qPCRs are listed in the supplemental data (available at www.jneurosci.org as supplemental material). In all cases, data were expressed as means $\pm \mathrm{SE}$ of at least three independent experiments. Statistical analysis was performed by unpaired twotailed Student's $t$ test and considered significant at $p<0.05$.
CHOP knockdown. CHOP ShRNA (CHOP-Sh) and control CHOP RNAi (CHOP-C) were purchased from Sigma, and the sequences are as follows: CHOP-Sh, 5'-GAAACGAAGAGGAAGAATCA-3'; CHOP-C 5'-CGGAAGTGTACCCAGCACC-3'.

Antibodies and reagents. Antibodies used for this study included the following: rabbit polyclonal anti-phospho-S6 (Ser234/Ser235) (catalog \#2211), mouse monoclonal anti-total S6 (catalog \#2317), rabbit polyclonal anti-phospho-Akt (Ser473) (catalog \#9271), rabbit polyclonal anti-S6K (catalog \#9202), rabbit polyclonal anti-phospho-S6K (Thr389) (catalog \#9234), rabbit polyclonal anti-Tsc1 (catalog \#4906), and rabbit polyclonal anti-Tsc2 (Thr1462) (catalog \#3611) (all from Cell Signaling Technology); rabbit polyclonal anti-Tsc2 (sc-893), mouse monoclonal anti-GADD153 (CHOP) (sc-7351), and goat polyclonal anti-Akt (sc1618) (all from Santa Cruz Biotechnology); and rabbit polyclonal antiGRP78 (SPA-826) and mouse monoclonal anti-heme oxygenase-1 (HO-1) (OSA-110) (from Stressgen). HRP-conjugated secondary antibodies were from VWR.

Western blot. Details can be found in the supplemental data (available at www.jneurosci.org as supplemental material).

ER stress induction. Thapsigargin (Tg) and Tunicamycin (Tn) were purchased from Sigma and used at a final concentration of $0.5 \mu \mathrm{M}$ and 4 $\mu \mathrm{g} / \mathrm{ml}$, respectively. Stocks of drugs were made in DMSO and freshly diluted in NB media at $20 \times$ of the final concentration before performing each experiment. The same amount of DMSO was used as vehicle-only control. Before ER stress induction, NB/B27 media was replaced with NB in the presence of penicillin/streptomycin for $4 \mathrm{~h}$, and drugs were then added for an additional 3, 6, and $24 \mathrm{~h}$. When included, rapamycin was used for $24 \mathrm{~h}$ in NB media at a final concentration of $20 \mathrm{nM}$.

Apoptosis quantification. The number of apoptotic cells was determined by Hoechst staining and trypan blue exclusion test. Embryonic day 17 rat neurons were plated on coverslips at a density of $10 \times 10^{4}$ cells $/ \mathrm{ml}$ and infected with lentivirus as described above. After 10 DIV, neurons were left untreated or treated for ER stress induction. For Hoechst quantification, neurons were fixed and stained with $5 \mu \mathrm{g} / \mathrm{ml}$ Hoechst (Invitrogen) for $5 \mathrm{~min}$ at room temperature. Neurons were then washed in PBS, mounted, and analyzed with a Leica DM RXA microscope equipped with epifluorescence. Apoptotic nuclei were counted under a $20 \times$ objective and expressed as the percentage of the total number of infected cells in the same field. Data are expressed as means $\pm \mathrm{SE}$ from at least three different experiments, and statistical analysis was performed by Student's $t$ test. For trypan blue exclusion test, neurons were harvested as described in flow cytometric analysis and resuspended in a $0.2 \%$ trypan blue solution (Sigma) prepared in HBSS for 5 min at room temperature. Apoptotic cells were evaluated under bright-field microscopy by counting nonviable cells (dye-positive) and viable cells (dyenegative) on hemocytometer fields.

For quantification of cell death at the single-cell level, the number of apoptotic cells was determined by counting cleaved caspase 3 (cc3) (Cell Signaling Technology catalog \#9664) positively stained neurons after immunofluorescent microscopy using a $20 \times$ objective. Data were expressed as a percentage of the total number of infected cells. The experiment was performed in triplicate, and at least 300 cells per experiment were counted. Statistical analysis was performed by unpaired two-tailed Student's $t$ test and considered significant at $p<0.05$.

Immunocytochemical analysis. Details can be found in the supplemental data (available at www.jneurosci.org as supplemental material).

Mitochondrial ROS. Rat hippocampal neurons were cultured in NB media for $24 \mathrm{~h}$, followed by incubation with $100 \mathrm{~nm}$ MitoTracker Red $\mathrm{CM}-\mathrm{H}_{2}$ XRos dye (MT-Red) (Invitrogen) for $30 \mathrm{~min}$ before being processed for immunofluorescence and stained with Hoechst. Oxidative stress was quantified by counting the number of MT-Red-labeled cells under an epifluorescent microscope with a rhodamine filter and expressed as the average percentage of MT-Red-labeled cells from three independent experiments.

Flow cytometric analysis. Neurons cultured in NB media for $24 \mathrm{~h}$ were harvested by $5 \mathrm{~min}$ incubation at $37^{\circ} \mathrm{C}$ with $15 \mathrm{U} / \mathrm{ml}$ papain (Worthington) made in HBSS containing $10 \mathrm{~mm} \mathrm{MgCl}_{2}, 1 \mathrm{~mm}$ kynurenic acid, 10 mM HEPES, and penicillin/streptomycin. Before dissociation, a solution of $7 \mathrm{mg} / \mathrm{ml}$ trypsin inhibitor (Sigma) was added to stop the reaction. 
Neurons were then collected by centrifugation, washed, and resuspended in NB media at $2 \times 10^{6}$ cells $/ \mathrm{ml}$. Neurons were divided into two aliquots, which were incubated in the absence or presence of 100 nM MitoTracker Red $\mathrm{CM}-\mathrm{H}_{2} \mathrm{XRos}$ dye (Invitrogen). After $20 \mathrm{~min}$ at $37^{\circ} \mathrm{C}$, neurons were collected by centrifugation, rinsed, and fixed in $4 \%$ paraformaldehyde made in PBS for 15 min at room temperature. After fixation, neurons were washed and resuspended in $200 \mu \mathrm{l}$ for analysis. Flow cytometric analysis was performed with Dako MoFlo equipped with Spectra-physics laser model 177 with an emission at 488 and a strength of $100 \mathrm{~mW}$. Data were analyzed with Summit 4.3 software (Dako). Gating was performed before the collection of data to remove apoptotic cells and cellular debris. Mean fluorescence intensity of MT-Red was calculated by subtracting for each sample the fluorescence-activated cell sorting (FACS) measurement obtained in the absence of the dye (background) to the measurement obtained in the presence of the dye.

\section{Results}

TSC and mTOR are dynamically regulated under ER stress

Because some of the most severe manifestations of TSC disease are in the CNS, we investigated the role of the TSC1/TSC2 complex in the neuronal response to ER stress. We treated rat hippocampal neurons with two widely used ER stress inducers: the ER-Ca ${ }^{2+}$-ATPase blocker Tg and the N-glycosylation inhibitor Tn (Li et al., 2000; Urano et al., 2000). To determine the optimal doses for these ER stress-inducing chemicals in neurons, we performed dose/response curves $(0.1-5 \mu \mathrm{M}$ for Tg; $1-12 \mu \mathrm{g} / \mathrm{ml}$ for $\mathrm{Tn})$ using wild-type rat hippocampal neurons and assessed cell death as the outcome. Expression of UPR-regulated genes GRP78 and $C H O P$ confirmed ER stress induction already at the lowest concentrations used for both drugs (supplemental Fig. $1 A-C$, available at www.jneurosci.org as supplemental material). As expected, cell death assessed by Hoechst staining (supplemental Fig. $1 D, E$, available at www.jneurosci.org as supplemental material) and trypan blue exclusion assay (supplemental Fig. $1 F$, available at www.jneurosci.org as supplemental material) showed that the percentage of apoptotic neurons increased in a dose-dependent manner for both $\mathrm{Tg}$ and $\mathrm{Tn}$. For the purpose of this study, we decided to use $0.5 \mu \mathrm{M}$ for $\mathrm{Tg}$ and $4 \mu \mathrm{g} / \mathrm{ml}$ for Tn because, at these doses, we observed a robust ER-stress-induced UPR activation and ER-stress-induced cell death of at least 50-60\% neuronal cells.

When assessing the effect of ER stress on the Akt/mTOR pathway, we found a response that varied with duration of treatment. Tg treatment led to an initial activation of mTOR as evidenced by increased phosphorylation of S6 ribosomal protein (phospho-S6 Ser235/236) (Fig. 1A,D). In contrast, longer exposure to Tg (24 h) correlated with a progressive decrease in Akt activity (phospho-Akt Ser473) and in the phosphorylation of Tsc2 at Thr1462 (Fig. 1 A,C,E), a known Akt phosphorylation site (Inoki et al., 2002; Potter et al., 2002). Thr1462 phosphorylation is known to inhibit TSC complex activity (Inoki et al., 2002; Manning et al., 2002). Accordingly, we observed inhibition of the downstream mTOR pathway, as indicated by decreased phosphorylation of S6 at $24 \mathrm{~h}$ (Fig. 1 A,D). ER stress was confirmed by the time-dependent increase in the expression of the UPRregulated gene, GRP78. Prolonged ER stress $(24 \mathrm{~h})$ correlated with expression of the proapoptotic UPR regulated gene $\mathrm{CHOP}$ and with apoptosis as shown by activated (cleaved) caspase 3 . Tunicamycin treatment, an alternative method of inducing ER stress, produced similar results in neurons (Fig. $1 B-E$ ). To investigate whether regulation of TSC1/TSC2 complex activity under ER stress also occurred in non-neuronal cells, we treated HEK293T and MEFs with ER stress inducers. We found that ER stress also induced transient mild activation of Akt, phosphory- lation of Tsc2, and phosphorylation of S6, followed by inhibition of this pathway at $24 \mathrm{~h}$ (supplemental Fig. $2 A, B$, available at www.jneurosci.org as supplemental material). These data indicate that activity of the TSC1/TSC2 complex is dynamically regulated in cells undergoing ER stress and may mediate the modulation of mTOR activity in response to ER stress.

\section{Loss of Tsc correlates with an mTOR-dependent ER stress response in neurons}

Having identified dynamic regulation of the TSC1/TSC2 complex activity under ER stress, we hypothesized that neurons lacking TSC activity would display features of ER stress at baseline attributable to constitutive activation of mTOR and high levels of protein synthesis. Therefore, we investigated ER stress response in neurons after RNAi-mediated knockdown of the Tsc2 gene. Rat hippocampal neurons were infected after 1 DIV with a lentivirus expressing $T s c 2$ gene plasmid-based short hairpin RNA (Tsc2-Sh) or a control lentivirus expressing shRNA against the luciferase gene (GL3-Sh). Because we have shown previously that knockdown of Tsc2 produces the same morphological and biochemical changes as Tsc1 knock-out in dissociated cells (Choi et al., 2008), we used Tsc2 knockdown neurons as an in vitro model to examine neuronal ER stress.

In Tsc2 knockdown neurons, there was a significant increase (3.5-fold) in the mRNA of CHOP as assessed by real-time qRTPCR (Fig. 2A). Also upregulated was the CHOP upstream regulator ATF4 (2.5-fold) (Fawcett et al., 1999; Harding et al., 2000; Ma et al., 2002) and to some extent (1.5-fold) ER stress sensor GRP78. Treatment of Tsc2 knockdown hippocampal neurons with rapamycin reduced $C H O P, A T F 4$, and GRP78 mRNA levels to baseline, indicating that the increase was mTOR dependent. Consistent with the increased CHOP mRNA levels in the Tsc2deficient hippocampal cultures, immunocytochemical analysis revealed that, in the Tsc2-Sh infected cultures, $13.3 \%$ of neurons had CHOP nuclear expression and 6.1\% had CHOP cytosolic expression compared with $0.7 \%$ CHOP nuclear expression and $0.1 \%$ CHOP cytosolic expression for control infected neurons (Fig. $2 B, C$ ).

$\mathrm{CHOP}$ is a proapoptotic transcription factor that is expressed and translocated into the nucleus under ER stress (Oyadomari and Mori, 2004). Because Tsc2 knockdown neurons demonstrated elevated CHOP expression at baseline, we investigated its expression and localization in Tsc-deficient neurons treated with Tg. Exposure to Tg significantly increased CHOP protein nuclear expression in Tsc2-deficient neurons compared with control cultures as assessed by immunocytochemical analysis (Fig. 2D,E). Together, these data show that loss of a functional TSC1/TSC2 complex in hippocampal neurons lowers the threshold for activation of UPR-regulated genes.

\section{Tsc2-deficient neurons show increased basal and ER-stress- induced cell death}

Although ER-stress-activated signaling is a protective cellular response to reduce ER load, prolonged ER stress often leads to cell death by apoptosis (Rao et al., 2001). To assess the effects of activating UPR response, we treated Tsc2 knockdown and control neuronal cultures with the ER stress inducers Tg or Tn for 3, 6 , and $24 \mathrm{~h}$. Knockdown of Tsc activity was confirmed by the reduced Tsc2 protein level and constitutively high S6 and S6K phosphorylation (Fig. 3A,B). Exposure to either Tg or Tn induced cellular ER stress as seen by the gradual increase in the expression of the ER stress sensor GRP78. Western blot analysis showed that Tsc 2 knockdown neurons had a small but significant 
A.
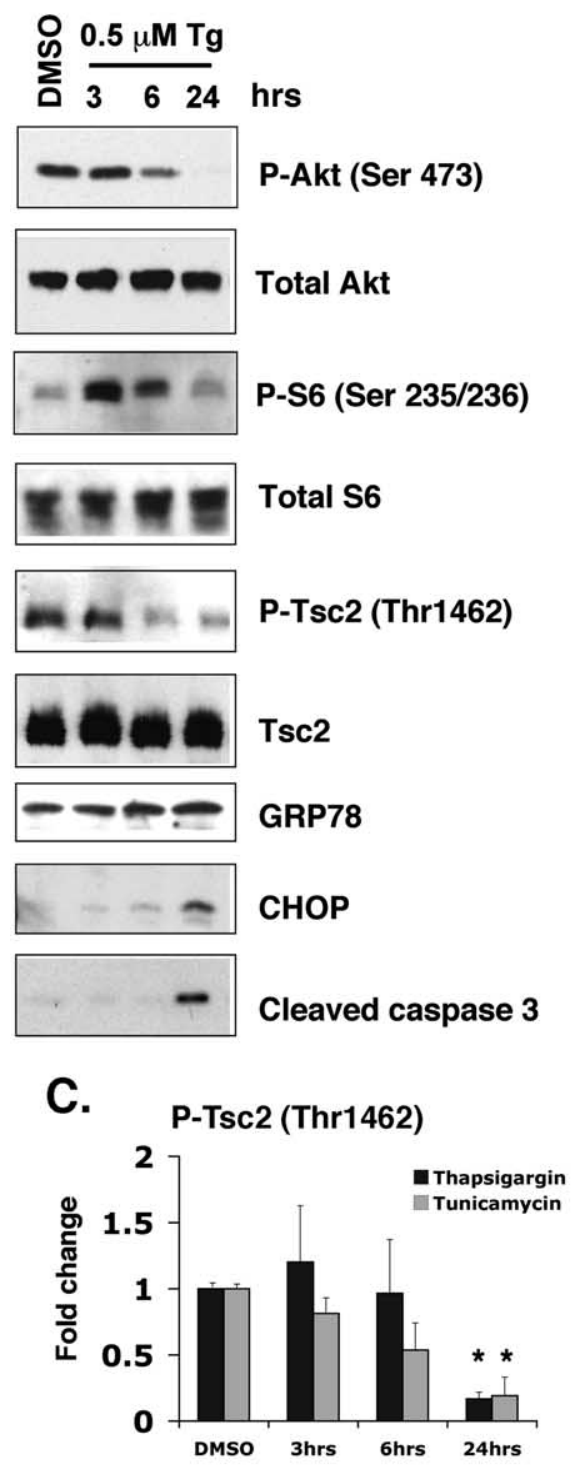

E.

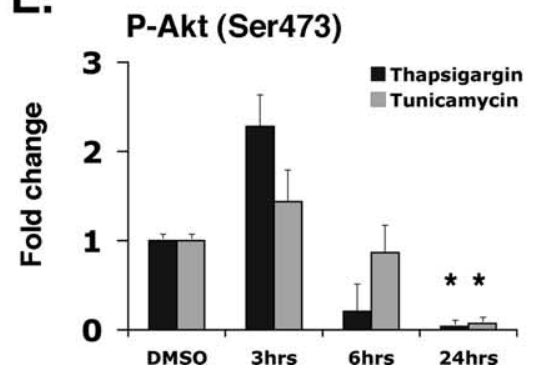

B.
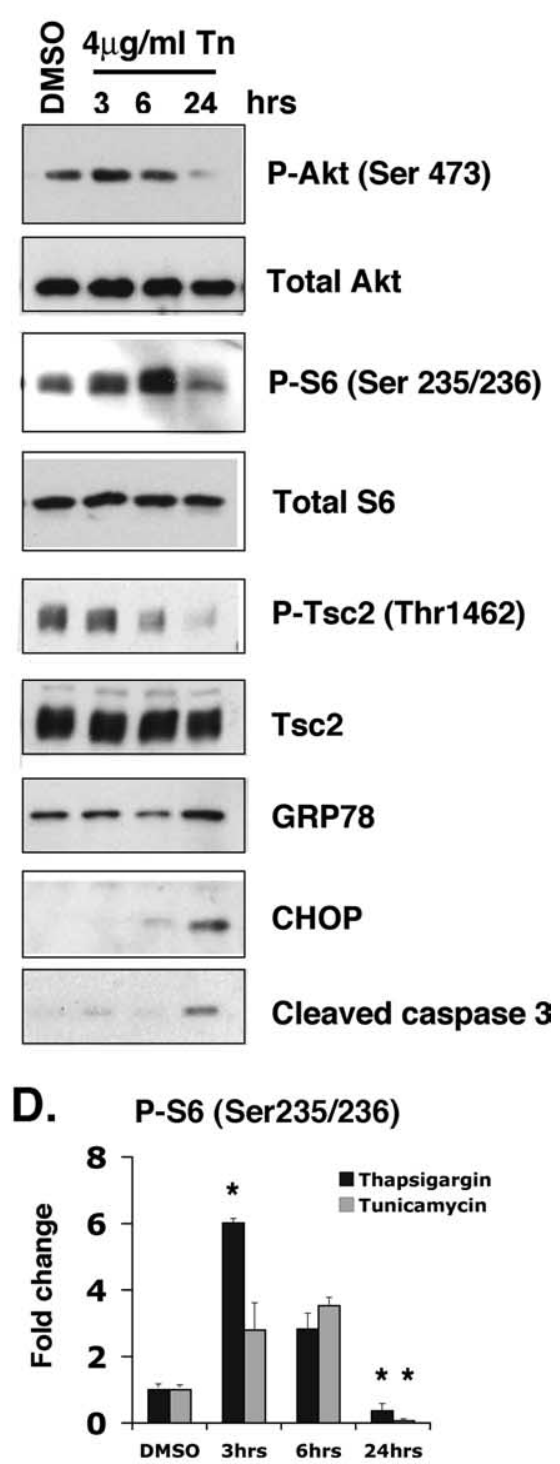

Figure 1. Regulation of the Tsc1/Tsc2 complex by ER stress. $\boldsymbol{A}, \boldsymbol{B}$, Rat hippocampal neurons were treated with vehicle (DMSO) or with $0.5 \mu \mathrm{m} \operatorname{Tg}(\boldsymbol{A})$ or with $4 \mu \mathrm{g} / \mathrm{ml} \operatorname{Tn}(\boldsymbol{B})$ for 3, 6, and $24 \mathrm{~h}$ to induce ER stress. Western blot analysis shows that ER stress induction modulates activity of the mTOR pathway (phospho-S6 Ser235/236). The regulation of the mTOR pathway closely parallels the decreased phosphorylation of Tsc2 (on Thr1462) by Akt. Equal loading is shown by probing with the antibodies against total Tsc2, total S6, and total Akt. C-E, Quantification of fold change of phospho-Tsc2 (Thr1462) (C), phospho-S6 (Ser235/ 236) (D), and phospho-Akt (Ser473) (E) after ER stress induction by Tg and Tn. Values were normalized against total Akt level and are represented as mean fold change relative to DMSO from at least three independent experiments. Statistical analysis was performed by a two-tailed $t$ test with an adjusted significant $\left({ }^{*}\right) p$ value $<0.017$ after Bonferroni's correction for multiple pairwise comparisons.

increase in the levels of CHOP protein expression at baseline compared with control-infected neurons, which was consistent with the observed increased basal transcription of CHOP mRNA. No differences were observed in the baseline and in the ER-stress-induced GRP78 levels between the control and Tsc-deficient neurons (supplemental Fig. $3 A, B$, available at www. jneurosci.org as supplemental material).

The effects of ER stress induction on neuronal viability were then monitored using an antibody for cleaved (active) caspase 3 on Western blots. In control neurons, Tg or Tn treatments induced cleavage of caspase 3 only after $24 \mathrm{~h}$, whereas in Tsc2-deficient neurons, cc3 was already detectable at baseline and further increased shortly after $(3 \mathrm{~h})$ ER stress induction (Fig. 3A,B). Similarly, as assessed by Hoechst staining, a higher proportion of Tsc2 knockdown neurons showed a significant increase in apoptotic nuclei at baseline and after short $\mathrm{Tg}(3 \mathrm{~h})$ (Fig. $3 C$ ) or Tn (3 and $6 \mathrm{~h}$ ) treatment (Fig. $3 E$ ). Similar results were obtained when assessing baseline cell death by trypan blue exclusion assay for Tg (Fig. 3D) and Tn (Fig. $3 F)$. To further confirm induction of apoptosis in Tsc2 knockdown cells, we assessed cytoplasmic levels of cytochrome $c$, a marker of early apoptosis (Ferri and Kroemer, 2001; Rao et al., 2001). Consistent with the higher level of baseline apoptosis, we detected cytochrome $c$ release in the cytosolic fraction of Tsc2-deficient neurons only (Fig. 3G). Densitometric quantification of cytosolic and mitochondrial cytochrome $c$ levels was performed on three independent experiments and revealed a 4.9-fold increase in the cytosolic cytochrome release in Tsc2-deficient neurons compared with controls $\left({ }^{*} p<0.01\right.$ by $t$ test). In cells under ER stress, the inositol requiring enzyme 1 (IRE1) pathway is responsible for the alternative splicing of the XBP-1 transcript (Lee et al., 2002). Interestingly, compared with neurons infected with control virus, Tsc2-deficient neurons had a more robust ER stress-induced activation of the IRE1 pathway during both Tg and Tn treatment, as shown by XBP-1 splicing (supplemental Fig. $4 A, B$, available at www.jneurosci.org as supplemental material). Together, these findings suggest that lack of Tsc activity in cultured hippocampal neurons correlates with increased ER-stress-induced cell death via activation of the mitochondrial death pathway.

Tsc-deficient neurons have increased oxidative stress and undergo cell death via a CHOP-dependent mechanism $\mathrm{CHOP}$ is a proapoptotic transcription factor that promotes apoptosis by modulat- 


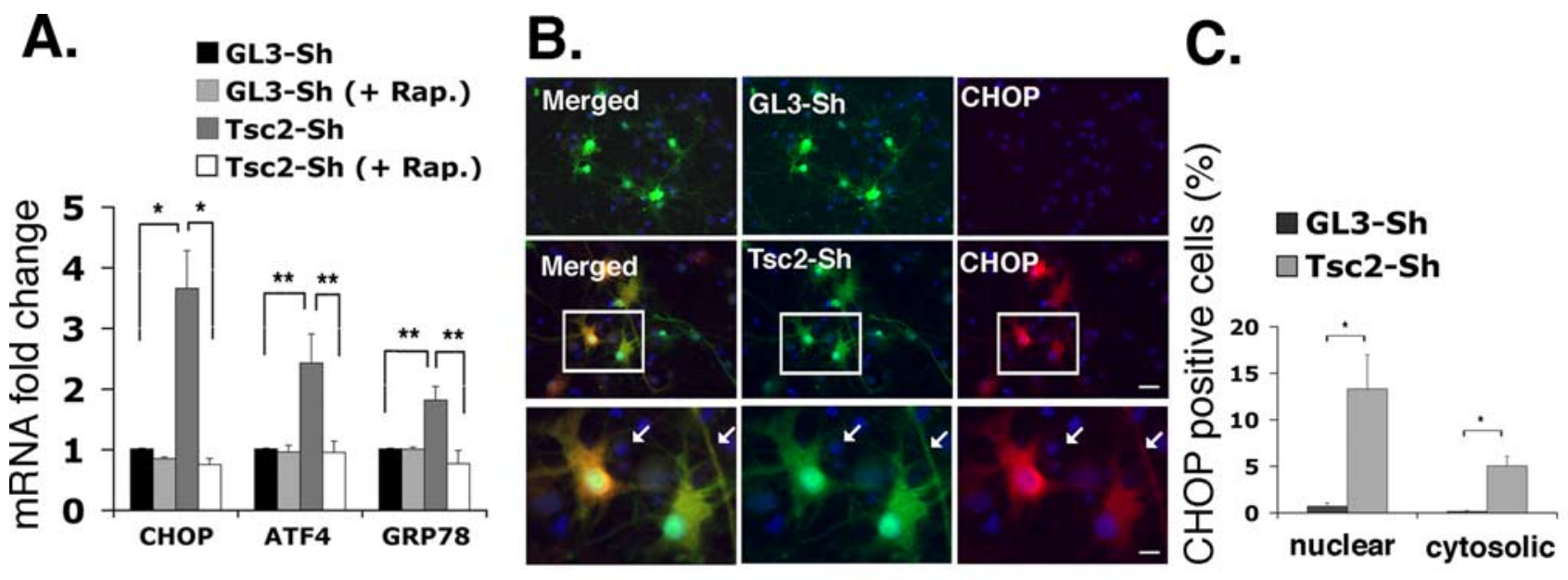

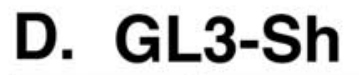
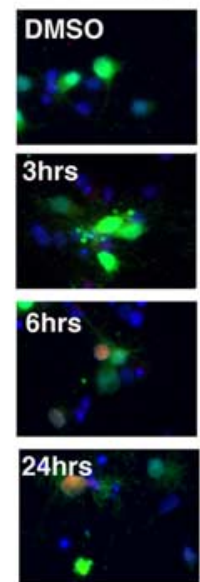

Merged
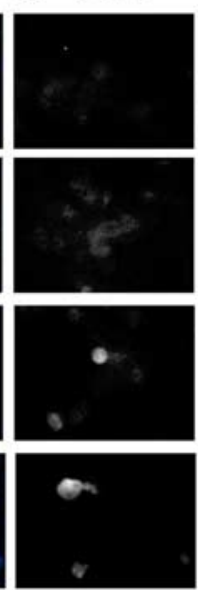

CHOP
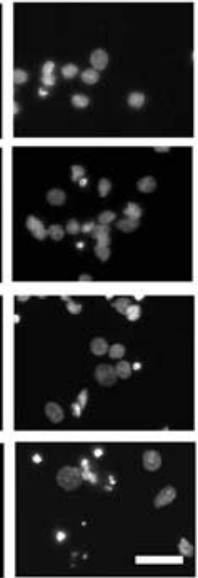

Hoechst
Tsc2-Sh
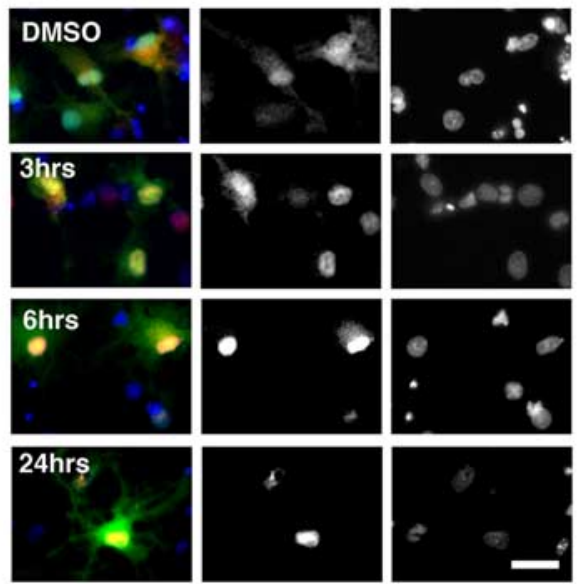

CHOP

Merged

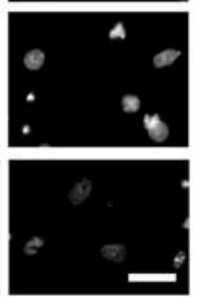

Hoechst

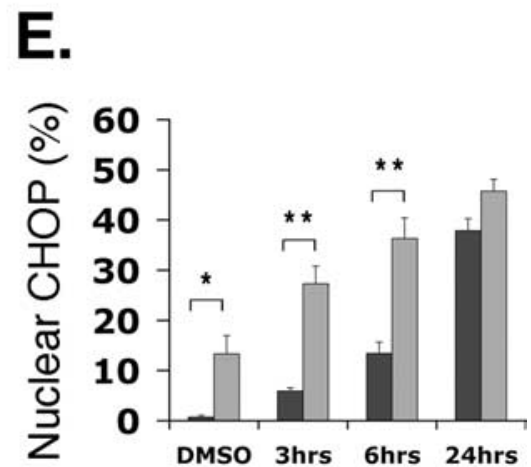

Figure 2. Regulation of UPR genes in Tsc-deficient neurons at baseline and after ER stress induction. $A$, Real-time qRT-PCR of total RNA from rat hippocampal neurons infected with GL3-Sh (control) and Tsc2-Sh RNAi lentivirus. The ER stress regulated genes CHOP, ATF4, and GRP78 are increased in the Tsc2-deficient neurons in an mTOR-dependent manner as shown by a direct comparison of the effect of rapamycin (Rap.; $20 \mathrm{~nm}$ for $24 \mathrm{~h}$ ) in each genotype. Significant $p$ values are as follows: ${ }^{*} p<0.01$ and ${ }^{* *} p<0.05$. Values normalized against GAPDH represent means of at least three independent experiments, and error bars represent SE. B, IF analysis of control and Tsc2-Sh infected neurons stained with CHOP antibody (red). GFP fluorescence (green) was used to identify infected neurons. Scale bar, $50 \mu \mathrm{m}$. Higher magnification of CHOP-positive neurons in the Tsc2-infected cultures (white box) is shown in the bottom panel. Scale bar, $20 \mu \mathrm{m}$. $\boldsymbol{C}$, Quantification of IF analysis shows a significant increase in CHOP nuclear and cytosolic staining in Tsc2-deficient neurons ( ${ }^{*} p<0.05$ ). Data represent means of three different experiments, and error bars represent SE. At least 300 cells were counted in each experiment, and statistical analysis was performed by the Student's $t$ test. $\boldsymbol{D}$, Representative IF images of control GL3-Sh and Tsc2-deficient neurons treated with DMSO (vehicle) or Tg for 3,6, and $24 \mathrm{~h}$ and stained with CHOP antibody. In the merged panels, infected neurons are in green, $\mathrm{CHOP}$ antibody in red, and Hoechst staining in blue. Scale bar, $50 \mu \mathrm{m}$. E, Quantification of nuclear expression from at least three different experiments per time point. Values are expressed as means, and error bars represent $S E$. $p$ values determined by Student's $t$ test are as follows: ${ }^{*} p<0.05,{ }^{* *} p<0.01$.

ing the expression of proteins that regulate cell survival and death pathways (Oyadomari and Mori, 2004). In particular, CHOP has been found to affect expression and localization of $b c l 2$ family members and influence the cellular redox status (McCullough et al., 2001; Marciniak et al., 2004). To determine which of these CHOP targets were affected in Tsc-deficient neurons, we compared the mRNA levels of survival and oxidative stress regulated genes by qRT-PCR (Fig. 4A). Tsc2 knockdown did not change the expression of the prosurvival factor $b c l 2$ or of the cellular antioxidant defense gene thioredoxin $2(\operatorname{Tr} x-2)$. Instead, we observed a significant mTOR-dependent increase in the expression (3.5-fold) of the antioxidant enzyme heme oxygenase-1 (HO-1) and of the ER oxidoreductase enzyme ERO1 $\alpha$. HO-1 protein levels were also increased in Tsc2-deficient neurons, and, during rapamycin treatment, this increase was blocked (Fig. 4B,C). However, under the same conditions, rapamycin treatment was not sufficient to prevent cell death.
HO-1 is a member of the heat shock family (Hsp32), and its expression is induced when cells experience oxidative stress ( Takahashi et al., 2004), whereas the ERO1 $\alpha$ is a glycosylated flavoenzyme implicated in oxidative protein folding and ROS production in the ER by promoting disulphide bond formation (Harding et al., 2003; Sevier and Kaiser, 2008). Therefore, we asked whether Tsc deficiency would induce increased production of ROS. Control and Tsc2-deficient rat hippocampal neurons were treated in culture with MT-Red (Fig. 4D,E). MT-Red generates fluorescence only during oxidation by superoxide produced by mitochondria (Kim et al., 2002). Quantification of MTRed-labeled cells under an epifluorescent microscope was performed from three independent experiments and revealed a 2.6-fold increase in the percentage of Tsc2-deficient-positive neurons compared with control-infected cells (control, $14.3 \pm$ $2.5 \%$ vs Tsc2-deficient neurons, $37.4 \pm 1.4 \% ; n=250$ cells per experiment; ${ }^{\star} p<0.001$ by $t$ test). MT-Red accumulation, as as- 
A. Thapsigargin

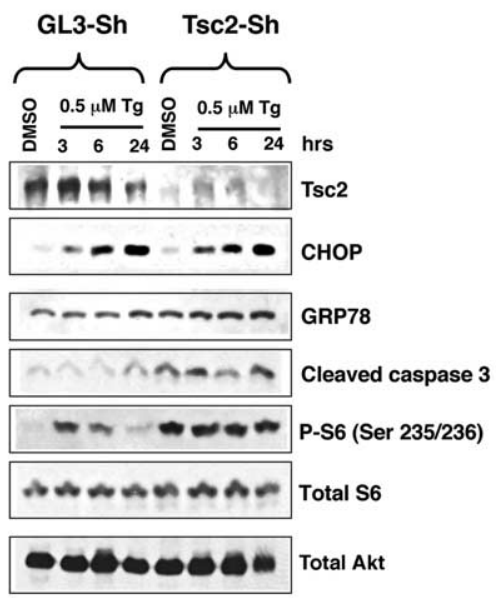

B. Tunicamycin

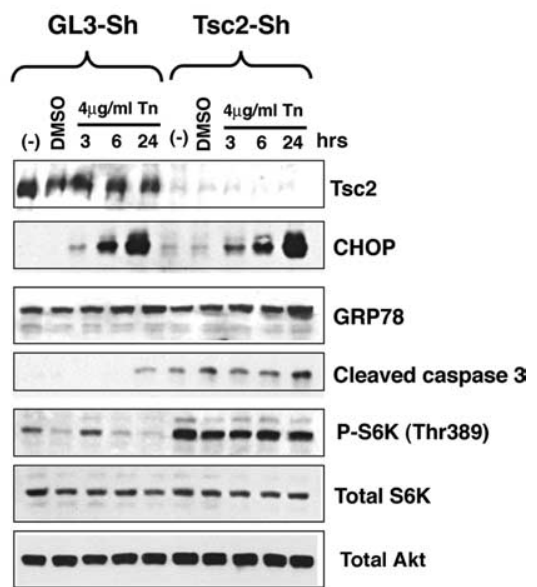

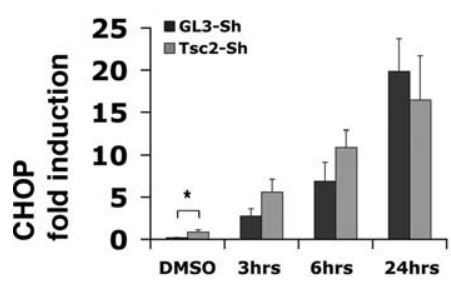

C. Thapsigargin
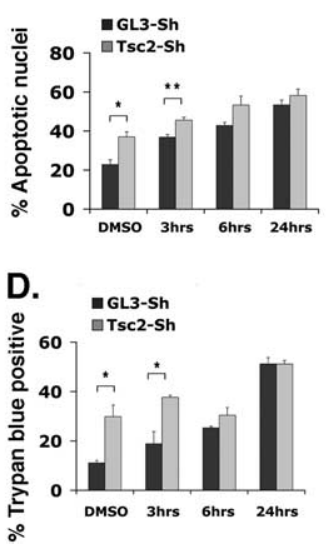

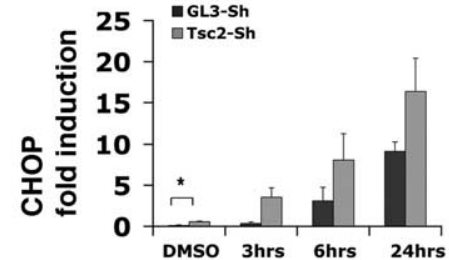

E. Tunicamycin

G.
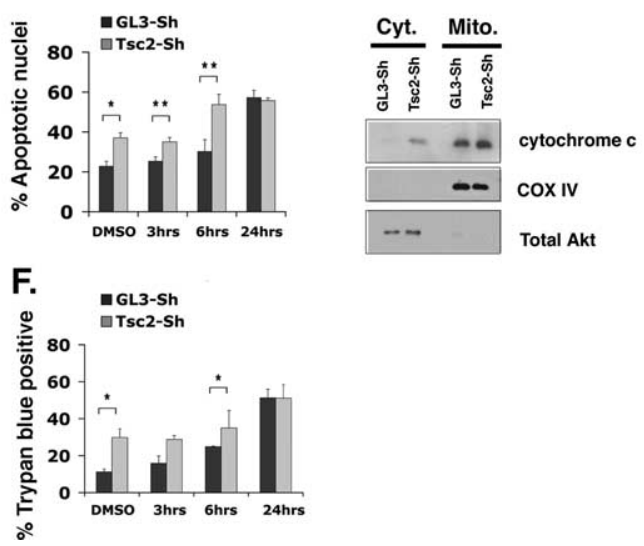

Figure 3. Lack of Tsc activity correlates with increased CHOP expression. Representative Western blots of protein lysates from GL3-Sh- and Tsc2-Sh-infected hippocampal neurons after ER stress induction. Neurons were left untreated ( -$)$, treated with vehicle (DMSO), with $0.5 \mu \mathrm{M} \mathrm{Tg}(\boldsymbol{A})$, or with $4 \mu \mathrm{g} / \mathrm{ml} \operatorname{Tn}(\boldsymbol{B})$ for 3, 6, and $24 \mathrm{~h}$. At baseline, Tsc2-deficient neurons have increased cleaved caspase 3. The densitometric quantification of $\mathrm{CHOP}$ protein induction represents means of three independent experiments, and error bars represent SE. Values were normalized to total Akt level, and statistical analysis was performed by a two-tailed $t$ test with an adjusted significant ${ }^{*} p$ value $<0.0125$ after Bonferroni's correction for multiple pairwise comparisons. $\boldsymbol{C}-\boldsymbol{F}$, Quantification of cell death after $\operatorname{Tg}(\boldsymbol{C}, \boldsymbol{D})$ and $\operatorname{Tn}(\boldsymbol{E}, \boldsymbol{F})$ treatments of control and $\operatorname{TsC} 2$-Sh neurons by Hoechst staining $(\boldsymbol{C}, \boldsymbol{E})$ and trypan blue exclusion test $(\boldsymbol{D}, \boldsymbol{F})$. For each panel, data are expressed as means \pm SE from three independent sets of experiments per time point. Statistical analysis was performed with the Student's t test $\left({ }^{*} p<0.005,{ }^{* *} p<0.05\right.$ in $C_{;}{ }^{*} p<0.05$ in $\boldsymbol{D} ;{ }^{*} p<0.005,{ }^{* *} p<0.05$ in $\boldsymbol{E}$; ${ }^{*} p<0.05$ in $\left.\boldsymbol{F}\right)$. G, Neuronal fractionation of control and Tsc2-deficient neurons shows increased cytochrome c release into the cytosolic fraction of Tsc2-Sh neurons, indicating activation of the mitochondrial death pathway. Cytochrome c oxidase IV (COXIV) and total Akt were used as mitochondrial (Mito.) and cytosolic (Cyt.) fraction markers, respectively.

sessed by FACS analysis, revealed a shift of the MT-Red fluorescence distribution inTsc2-Sh cultures, indicating significantly increased fluorescence mean intensity (FMI) (Fig. 4F). A 1.7-fold increase in FMI of MT-Red was found in Tsc2-Sh cultures compared with control $\left({ }^{*} p<0.05\right.$ by $t$ test $)$. The higher levels of ROS and increased HO- 1 expression after Tsc2 silencing indicate a critical role for Tsc in regulating oxidative stress response in neurons.
Tsc-deficient neurons undergo cell death via a CHOP-dependent mechanism

The identification of increased cell death and ROS production in Tsc-deficient neurons led us to ask whether CHOP activity was necessary for these effects. To investigate this question, we silenced CHOP expression using RNAi. Rat hippocampal neurons were first infected with either GL3-Sh virus or Tsc2-Sh virus, and, after $6 \mathrm{~d}$, they were reinfected with lentiviral vectors expressing either a CHOP-Sh or control CHOP-C constructs. GL3-Sh- and Tsc2-Sh-infected neuronal cultures were then either left untreated or treated with Tg for ER stress induction. CHOP-Sh RNAi efficiently reduced baseline and $\mathrm{Tg}$ induced CHOP expression at both the RNA and the protein level in Tsc-deficient neurons and in Tg-treated GL3-Sh cultures (Fig. 5A,B). We found that, compared with CHOP-C virus, CHOP-Sh virus efficiently reduced the baseline and the ER-stress-induced HO-1 expression at both the mRNA and protein levels in Tsc2deficient neurons (Fig. 5C). Consistent with its role in promoting ERO1 $\alpha$ activation (Marciniak et al., 2004), CHOP knockdown reduced ERO1 $\alpha$ expression in Tsc2-deficient neurons (supplemental Fig. 5, available at www.jneurosci.org as supplemental material). A significant reduction was also identified in the oxidative stress response of Tsc2-deficient cultures infected with CHOP-Sh compared with those infected with CHOP-C virus (Fig. $5 D$, available at www.jneurosci.org as supplemental material). Quantification of MT-Red-positive neurons was performed on immunofluorescent images from three independent experiments after incubation with 100 nM MitoTracker Red CM$\mathrm{H}_{2} \mathrm{XRos}$ (at least 200 cells per experiment; Tsc2-Sh cultures infected with CHOP-C virus, $36.9 \pm 2.0$ vs Tsc2-Sh cultures infected with CHOP-Sh virus, $17.0 \pm 5.0$; ${ }^{*} p<0.05$ by $t$ test). Most importantly, CHOP silencing reduced cell death in Tsc2-deficient neurons by cleaved caspase staining by both Western blotting and at the single-cell level (Fig. 5B, $C, E, F$ ). Together, these data indicate that, in the setting of Tsc deficiency, CHOP upregulation plays a major role in both oxidative stress response and cell death induction.

Previous studies have shown that loss of TSC1/TSC2 complex activity correlates with an mTOR-dependent negative feedback on the phosphatidylinositol 3-kinase (PI3K)/Akt pathway, which in turn results in reduced Akt activation (Zhang et al., 2006). To investigate whether a similar inhibition was occurring in Tscdeficient neurons, we analyzed Akt at the phospho-Ser473 activation site using Western blot. When compared with control 
A.
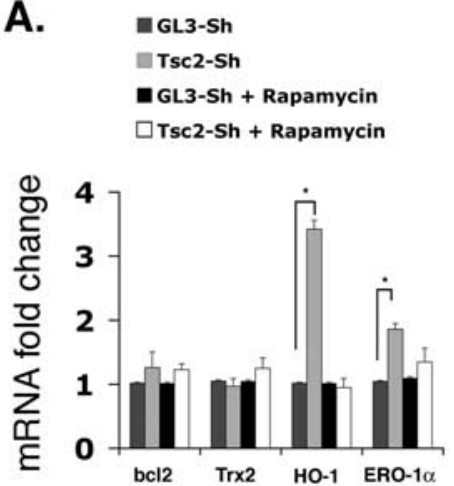

B.

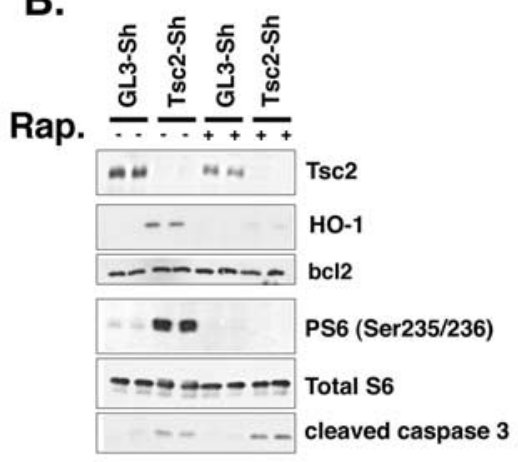

C.

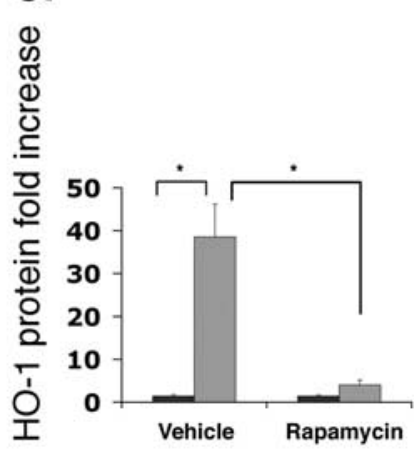

D.

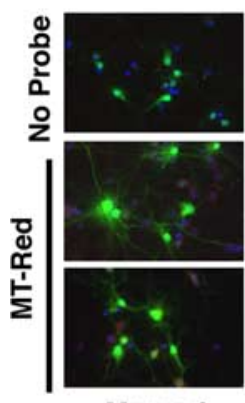

Merged
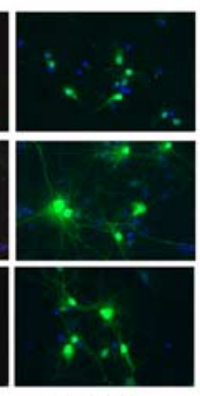

GL3-Sh
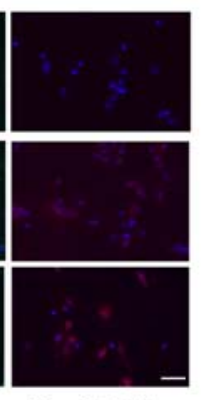

Red-ROS
E.

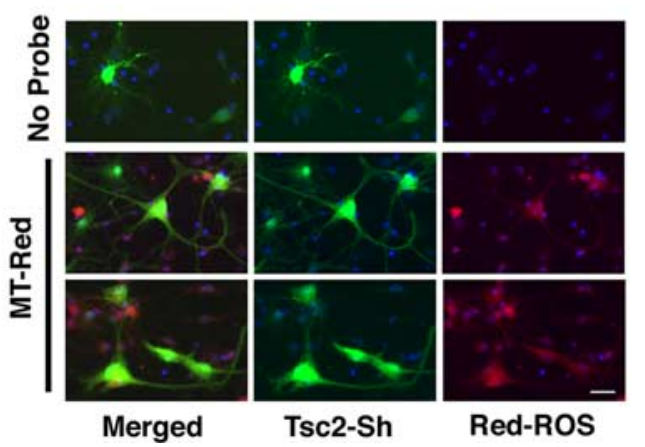

F.

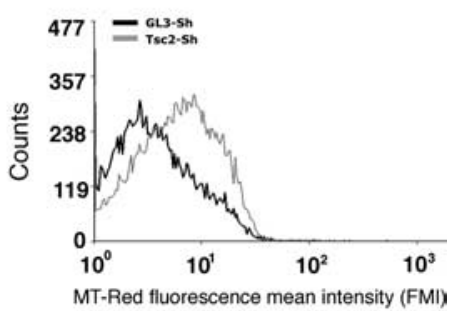

Figure 4. Lack of Tsc activity correlates with mTOR-dependent oxidative stress response. $\boldsymbol{A}$, Real-time qRT-PCR from RNA samples of GL3-Sh- and Tsc2-Sh-infected neurons untreated (-) or treated $(+)$ with $20 \mathrm{~nm}$ rapamycin for $24 \mathrm{~h}$. Data are normalized to GAPDH level and are expressed as means \pm SE of at least three different experiments $\left({ }^{*} p<0.01\right)$. $\boldsymbol{B}$, Representative Western blot of protein lysates from control and Tsc2-Sh hippocampal neurons untreated (-) or treated (+) with 20 nm rapamycin (Rap.) for 24 h. Increased H0-1 protein expression but not cleaved caspase 3 levels are reversed by rapamycin treatment in Tsc2-deficient neurons. Phospho-S6 was used to confirm mTOR downregulation by rapamycin, and total S6 was used as a loading control. $\mathbf{C}$, Quantification of H0-1 protein induction. Data are averages \pm SE from three different experiments. Statistical analysis was performed by a two-tailed $t$ test with adjusted significant $p$ values in the absence of rapamycin and in the presence of rapamycin ( ${ }^{*} p<0.025$ after Bonferroni's correction for multiple pairwise comparisons). $\boldsymbol{D}, \boldsymbol{E}$, ROS production is increased in Tsc-deficient neurons. Representative IF images of control (D) and Tsc2-deficient $(\boldsymbol{E})$ rat hippocampal neurons in the absence and in the presence of $100 \mathrm{~nm}$ MT-Red. Scale bar, $20 \mu \mathrm{m}$. $\boldsymbol{F}$, Representative distribution of the MT-Red FMI detected in control GL3-Sh- and Tsc2-Sh-infected cultures by flow cytometric analysis. The shift to the right on the MT-Red fluorescence distribution inTsc2-Sh cultures indicates increased FMI.

cultures, Tsc2-Sh-infected neurons had indeed lower basal levels of Akt activation that did not change after CHOP-Sh RNAi (Fig. $5 B$ ). These data indicate that reduced Akt activity in Tsc2deficient neurons is CHOP independent, and, although downregulated Akt might contribute to increased apoptosis in Tscdeficient neurons, knockdown of CHOP alone is sufficient to reduce both cell death and oxidative stress.

\section{In vivo identification of stress response in brains from $T s c 1^{c /-}$} $\mathrm{SynCre}^{+}$mice and in the tuber of a TSC patient

Our data demonstrated increased oxidative stress in Tsc2deficient hippocampal cultures in vitro. To determine whether a similar stress response occurs in vivo, we assessed levels of expression for CHOP and HO-1 in total brain lysates from $T s c 1^{\mathrm{c} /-} S y n-$ $\mathrm{Cre}^{+}$mice (neuronal Tscl knock-out) (Meikle et al., 2007). $\mathrm{Tscl}^{\mathrm{cl}-} \mathrm{SynCre}{ }^{+}$mice experience near-complete loss of Tsc1 expression in neurons and display neurological decline with median survival of $35 \mathrm{~d}$. Both the neurological abnormalities and the median survival are markedly improved when mutant mice are treated with rapamycin from P7 to P33 (Meikle et al., 2008). To investigate ER stress responses in vivo, we used $\mathrm{Tscl}^{\mathrm{c}-}-\mathrm{SynCre}{ }^{+}$ mice either untreated or treated with rapamycin. Both $\mathrm{CHOP}$ and $\mathrm{HO}-1$ protein levels were increased in $\mathrm{Tscl}^{\mathrm{cl}-}-\mathrm{SynCre}{ }^{+}$brain lysates and were reduced in mice treated with rapamycin (Fig. $6 A, B)$. Interestingly, $\mathrm{Tscl}^{\mathrm{cl}-} \mathrm{SynCre}{ }^{+}$mice taken off rapamycin after 3 weeks of treatment showed recurrence of $\mathrm{HO}-1$ expression (supplemental Fig. 6, available at www.jneurosci.org as supplemental material).

To extend these findings at the cellular level, immunohistochemical analysis for HO-1 was performed on control and $\mathrm{TsCl}^{\mathrm{cl}-}$ Syn$\mathrm{Cre}^{+}$brains. Costaining with phospho-S6 antibody was used to identify neurons with increased mTOR activity. Phospho-S6positive dysplastic cells identified in the hippocampus and the red nucleus of $\mathrm{Tscl}^{\mathrm{cl}-} \mathrm{SynCre}{ }^{+}$brains were also positive for HO-1 (Fig. $6 C, D)$. Furthermore, rapamycin treatment decreased phospho-S6 staining and $\mathrm{HO}-1$ expression in $\mathrm{Tscl}^{\mathrm{cl}-} \mathrm{SynCre}{ }^{+}$brains to levels comparable with controls (Fig. 6D).

To determine whether our findings could be extended to human TSC disease, we performed immunohistochemical analysis on sections from a tuber of a 4-year-old TSC patient. Giant cells with increased mTOR activity were identified in the human tuber by phospho-S6 antibody staining (Fig. 6E). CHOP and HO-1 colabeling was observed in $44 \%$ ( 80 of 115 counted) and 57\% (70 of 123 counted) of the phospho-S6-positive cells, respectively. No CHOP or HO-1 staining was observed in the perituber brain regions (Fig. $6 F$ ) or in the brain of a non-TSC patient with focal dysplasia (Fig. $6 G$ ). In agreement with previous reports, balloon cells that are typically found in focal dysplasias showed some phospho-S6 and SMI-311 staining (Lurton et al., 2002; Baybis et al., 2004). Together, these findings strongly suggest that the ER 
A.

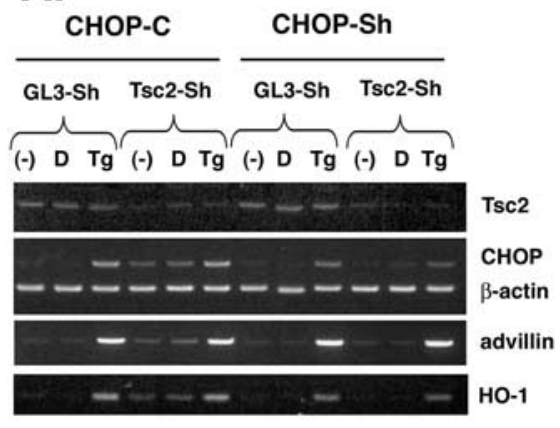

B.

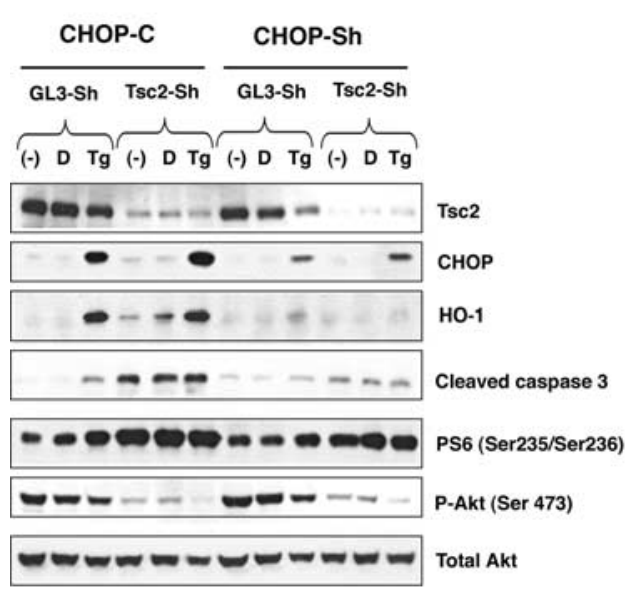

C.

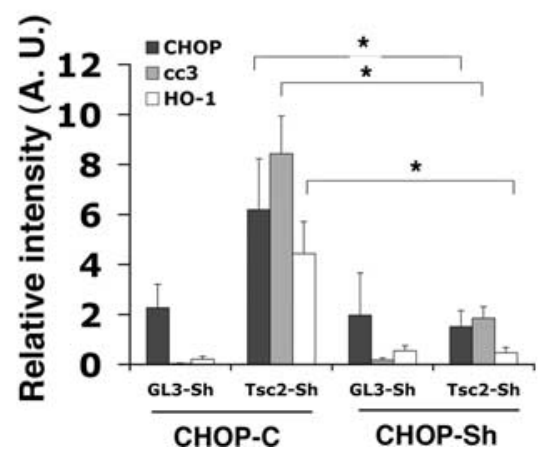

D.

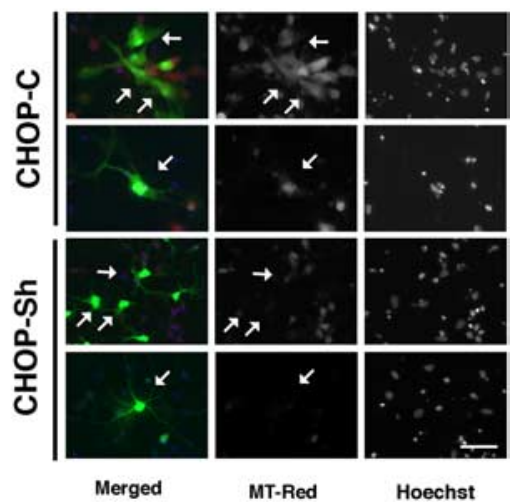

E.

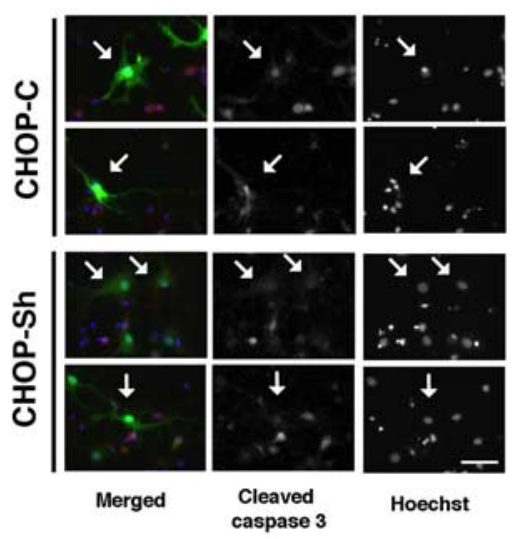

F.

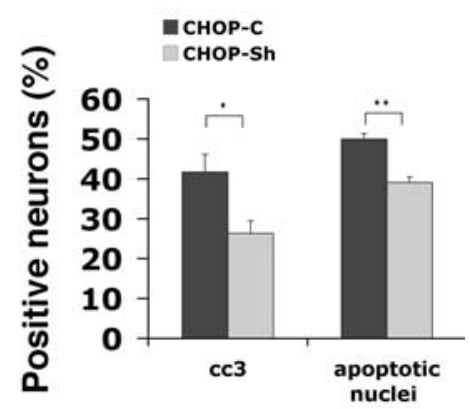

Figure 5. Silencing of CHOP expression in GL3-Sh and Tsc2-Sh neurons. $\boldsymbol{A}, \boldsymbol{B}$, Control and Tsc2-Sh neurons infected with CHOP-C and CHOP-Sh RNAi lentivirus. Neurons were left untreated (-), treated with DMSO-vehicle (D), or treated with $0.5 \mu \mathrm{M} \mathrm{Tg}$ for $24 \mathrm{~h}$. Total RNA and protein lysates were prepared for RT-PCR $(\boldsymbol{A})$ and Western blot analysis $(\boldsymbol{B})$, respectively. $\boldsymbol{A}$, CHOP knockdown reduces oxidative stress response as shown by HO-1 expression at the RNA level. A downstream target of CHOP, advillin (Wang et al., 1998), was used to confirm inhibition of CHOP activity, and $\beta$-actin was used as a loading control. $\boldsymbol{B}$, In Tsc2-deficient neurons, CHOP-Sh RNAi abrogates H0-1 expression and partially rescues cell death. Increased S6 phosphorylation, as detected by Western blot analysis, confirms mTOR activation in Tsc2-deficient neurons. Total Akt confirms equal loading. $\mathbf{C}$, Quantification of oxidative stress response and cell death after $\mathrm{CHOP}$ knockdown. Level of $\mathrm{CHOP}, \mathrm{HO}-1$, and cleaved caspase 3 were quantified from three independent experiments by densitometry scans after immunoblotting. Values were normalized against total Akt and expressed as means \pm SE. Statistical analysis was performed by Student's $s$ test with an adjusted significant ${ }^{*} p$ value $<0.017$ after Bonferroni's correction for multiple pairwise comparisons. D, Effect of CHOP silencing on oxidative stress at the single-cell level in Tsc2-deficient neurons. Representative IF images of Ts2-Sh cultures (in green in the merged panels) infected with control CHOP-Cand CHOP-Sh after incubation with $100 \mathrm{~nm}$ MitoTracker Red $\mathrm{CM}_{2} \mathrm{H}_{2}$ XROS (MT-Red in red in the merged panels). Scale bar, $20 \mu \mathrm{m}$. $\boldsymbol{E}$, Effect of CHOP silencing on apoptosis at the single-cell level. IF analysis of cleaved caspase 3 staining (in red in the merged panels) of Tsc2-Sh neuronal cultures (in green in the merged panels) infected with control CHOP-C or CHOP-Sh RNAi. $F$, Quantification of the percentage of Tsc2-Sh-infected cultures positive for $c c 3\left({ }^{*} p<0.05\right)$ and apoptotic nuclei $\left({ }^{* *} p<0.001\right)$. Data are expressed as means \pm SE from three independent experiments with at least 200 cells per experiment counted.

and oxidative stress responses identified in vitro in the Tsc2 silenced hippocampal neurons are also present in vivo in both the Tsc knock-out mouse model and the human TSC brain.

\section{Discussion}

Despite recent progress identifying the genetic mutations and the signaling pathways associated with TSC pathology, the pathogenesis of the diverse neurological symptoms present in this disease remain poorly understood, and treatments are elusive. Here, we demonstrate that Tsc deficiency correlates with the upregulation of specific stress-related cellular responses both in vitro and in vivo (summarized in Fig. 6H). First, we detected ER overload and oxidative damage in Tsc2-deficient hippocampal neurons, in brains from $\mathrm{Tscl}^{c /-} \mathrm{SynCre}{ }^{+}$mice and in human TSC tissue. Second, we demonstrated that these cellular abnormalities are the consequence of constitutive mTOR activation because rapamycin treatment abolished stress responses both in vitro and in vivo. Third, we showed that neuronal stress responses in vitro increased vulnerability to cell death via activation of the mitochondrial death pathway and that silencing $\mathrm{CHOP}$ reduced apoptosis. The identification of similar stress responses in primary rodent hippocampal neurons with nearly complete $T s c 2$ gene silencing and in the human TSC brain highlight the damaging neuronal responses that result from mTOR hyperactivity.

We have shown recently that components of the TSC/mTOR pathway are differentially localized during the development of neuronal polarity, as defined by the elaboration of a single neuron and multiple dendrites (Choi et al., 2008). This fine regulation of TSC activity in neurons during the neuronal polarization process, together with the identification of multiple axon formation in neurons lacking Tsc, indicates a critical role for the TSC/mTOR pathway in axonal specification and connectivity. These findings, along with the identification of a critical role for TSC pathway in dendritic structure (Tavazoie et al., 2005), have highlighted the neuronal defects contributing to the neurological symptoms. In vivo studies using knock-out mice have indeed shown that loss of TSC in neurons correlates with anatomical brain abnormalities and neurological defects (Meikle et al., 2007).

In previous reports, loss of TSC1/TSC2 complex has been implicated in increased ER stress in MEFs from Tsc1 and Tsc2 knock-out mice (Ozcan et al., 2008). Al- 
A.

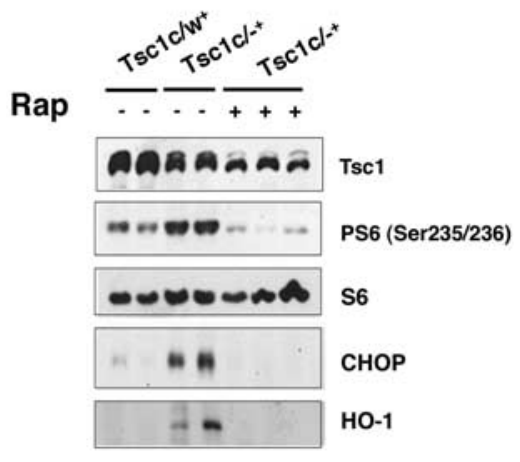

C.

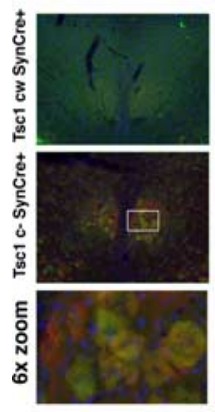

Merged

E.

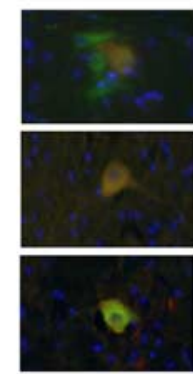

Merged

G.
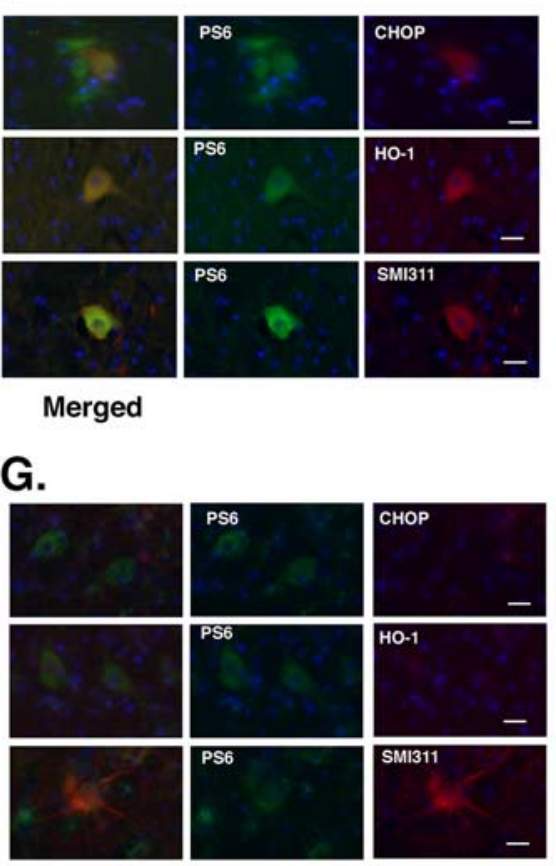

B.

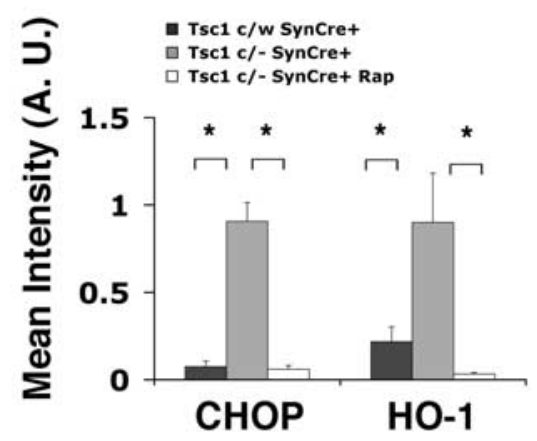

D.

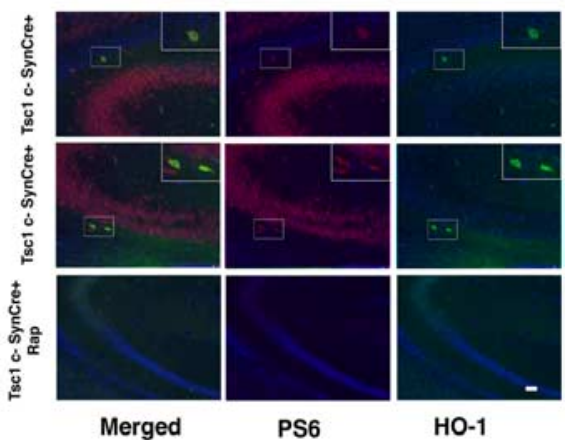

F.
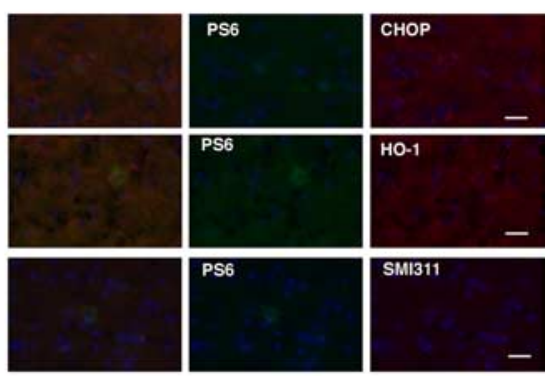

Merged

H.

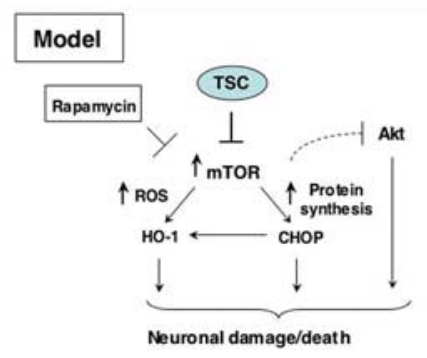

Merged

Figure 6. Upregulation of stress responses in the brain of Tsc-deficient mice. $\boldsymbol{A}$, Western blot of brain lysates from $\mathrm{Tsc}^{\mathrm{C} / \mathrm{w}}$ SynCre ${ }^{+}$(control), $\mathrm{Isc}^{\mathrm{Cl}^{\prime-}} \mathrm{SynCre}{ }^{+}$and $\mathrm{TsC}^{\mathrm{Cl} /}-\mathrm{SynC} \mathrm{Cre}^{+}$mice treated with rapamycin at $6 \mathrm{mg} / \mathrm{kg}$ every other day from P9 to P33. $\mathrm{TsCl}^{\mathrm{cl}-}$ SynC $\mathrm{Ce}^{+}$mice show reduced Tsc1 protein levels confirming inactivation of the $\mathrm{Tsc} 1$ gene. Increased phospho-S6 (Ser235/ 236) confirms the presence of active mTOR in the brain lysates from the $\mathrm{TsC}^{\mathrm{Cl}-}$ SynCre ${ }^{+}$mice. Occurrence of stress response is shown by increased expression of $\mathrm{CHOP}$ and $\mathrm{H} 0-1$. Inhibition of $\mathrm{mTOR}$ by rapamycin effectively reduces both $\mathrm{CHOP}$ and $\mathrm{HO}-1$ levels. Total $S 6$ was used as a loading control. B, Quantification of protein levels performed from the following: $\mathrm{Isc}^{\mathrm{C} / \mathrm{W}} \mathrm{SynC} \mathrm{Cre}^{+}$mice, $n=$

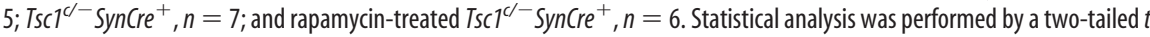
test with an adjusted significant ${ }^{*} p$ value $<0.017$ after Bonferroni's correction for multiple pairwise comparisons. $\mathbf{C}-\mathbf{G}$, Immunohistochemical detection of stress response in vivo. $C$, Immunofluorescent detection of H0-1 expression in phospho-S6-positive

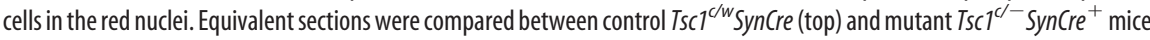
(middle). Scale bar, $50 \mu \mathrm{m}$. Higher magnification of the phospho-S6- and H0-1-positive cells (white box) is shown in the bottom

though MEFs display increased expression of the ER stress chaperone GRP78 and activation of the PERK signaling pathway, we did not detect any changes in GRP78 protein level (Fig. 3A) (supplemental Fig. 4, available at www.jneurosci.org as supplemental material) or PERK activation (data not shown) in neurons. Such differences may represent cell-type-specific responses. Our study suggests that neurons lacking Tsc have a basal activation of CHOP via the canonical ATF4 pathway (Fawcett et al., 1999; Harding et al., 2000; $\mathrm{Ma}$ et al., 2002). Because many extrinsic factors such as hypoxia, hypoglycemia, and exposure to natural and experimental toxins can lead to ER stress (Koumenis, 2006; Zhang and Kaufman, 2006), Tscdeficient neurons are more likely to be vulnerable to such insults.

\section{Implications of ER stress for} neurological manifestations of TSC

Epilepsy is by far the most common medical condition associated with TSC, occurring in $80-90 \%$ of patients. The relationship between ER stress and epilepsy is just starting to be investigated. For example, kainate-induced seizures in rats and depolarization in cultured rat hippocampal neurons lead to ER stress (Sokka et al., 2007). Moreover, increased UPR has been observed in hippocampi resected from patients with temporal lobe epilepsy (Yamamoto et al., 2006). Finally, ER overload attributable to abnormal trafficking of misfolded proteins has been proposed to occur in several epilepsy-related "channelopathies” (Hirose, 2006). Together,

panel. Scale bar, $10 \mu \mathrm{m}$. D, Immunofluorescent detection of H0-1 expression in ectopic neurons of the hippocampal region in mutant $\mathrm{SsCl}^{\mathrm{C} /}-\mathrm{SynCre}{ }^{+}$mice with or without rapamycin treatment. Treatment with rapamycin decreases both phospho-S6 and H0-1 expression. Scale bar, $50 \mu \mathrm{m}$. E-G, Immunohistochemical analysis on a cortical tuber resected from a 4-year-old TSC patient $(\boldsymbol{E})$, from the perituber region of a TSC patient $(\boldsymbol{F})$, and from a non-TSC patient with focal dysplasia $(\boldsymbol{G})$. Increased level of phospho-S6 staining indicates mTOR activation in the tuber. Compared with the sections in $\boldsymbol{F}$ and $\mathbf{G}$, elevated CHOP and HO-1 expression are specifically observed only in the giant cells from the tuber region of the TSC brain (E). Enlarged dysmorphic neurons were also identified by positive SMI-311 staining. Scale bar, $50 \mu \mathrm{m}$. $\boldsymbol{H}$, Model for mTOR-dependent neuronal dysfunction after TSC1/TSC2 loss. After loss of TSC function, uncontrolled mTOR hyperactivation results in an increase in protein synthesis and ROS production. Such overloaded cellular machinery results in ER and oxidative stress responses, which induce $\mathrm{CHOP}$ and $\mathrm{HO}-1$, respectively, and can be reversed by rapamycin. These cellular stress pathways together with downregulated Akt activity likely contribute to increased vulnerability to neuronal death and dysfunction. 
these findings indicate that seizures can exacerbate ER stress and underlying ER stress could potentially contribute to seizures by misfolding of synaptic proteins. This is particularly important in TSC disease because the vast majority of patients experience seizures and many of the cases are medically intractable. A better understanding of the relationship between the TSC/mTOR pathway, ER stress, and seizures may help to uncover novel therapies for intractable epilepsy in patients.

\section{Implications of oxidative damage in Tsc mutant brains}

Accumulating evidence has revealed a crosstalk between ER and oxidative stress responses, such that excessive ROS production can contribute to UPR induction and vice versa (Yokouchi et al., 2008). For instance, UPR-regulated genes can create an imbalance in the cellular redox status and release free radicals such as superoxide anions, leading to damage of ER-resident proteins (Verkhratsky and Petersen, 2002). The combined cellular insult that may arise from ER and oxidative stress has been proposed to further contribute to cell death by increasing the accumulation of ROS (Haynes et al., 2004). Our identification of an altered redox balance in Tsc-deficient neurons is consistent with previous reports of increased basal and growth factor-stimulated ROS in $T s c 2^{-/-}$MEFs (Finlay et al., 2005). In Tsc-deficient neurons, we found that silencing of $\mathrm{CHOP}$ was sufficient to reduce the oxidative stress response, thus indicating a tight-linked connection between these two cellular stress pathways.

The brain is highly sensitive to oxidative stress, which has been correlated with the pathogenesis of several neurological disorders (Reynolds et al., 2007). In particular, the cellular toxicities resulting from oxidative stress, such as massive calcium overload, energy depletion, and ROS production, are thought to affect neuronal function by lowering the cellular capacity to respond to stress. A number of studies have suggested that, although the response to stress offers homeostatic control of cellular function, a prolonged stress response itself can be toxic (Kaufman, 2002). For example, the expression of $\mathrm{HO}-1$, the rate-limiting enzyme for the degradation of the heme, is overall considered to be beneficial (Schipper, 2004b). However, excessive HO-1 can also contribute to the increase of carbon monoxide (CO) and/or free iron levels, which can have toxic effects on mitochondrial function (Ryter and Tyrrell, 2000; Barañano and Snyder, 2001; Schipper, 2004a). Expression of HO-1 in phospho-S6-positive ectopic neurons of $\mathrm{Tscl}^{c /-} \mathrm{SynCre} \mathrm{C}^{+}$mice and in the dysplastic cells of human tubers indicates a concomitant increase in mTOR activity and occurrence of oxidative stress in vivo. Importantly, mTOR inhibition in vivo reduced $\mathrm{CHOP}$ and $\mathrm{HO}-1$ expression. $\mathrm{mTOR}$ inhibitors have already been successfully used in several brainspecific TSC mouse models and shown to efficiently improve survival and neurological phenotypes (Ehninger et al., 2008; Meikle et al., 2008; Zeng et al., 2008). These results together with our study addressing the molecular targets affected by rapamycin treatment in vivo provide new insights into the cellular basis of the neuronal dysfunction in TSC.

In the future, it will be important to investigate the damaging effects that could arise from $\mathrm{HO}-1$ overproduction in the TSC brain, such as iron deposition or CO accumulation (Patel et al., 1996). For instance, a highly detrimental effect of iron deposition is the accumulation of free iron in the mitochondria as a result of increased oxidative stress. This would eventually cause mitochondrial dysfunction and energy production failure, affecting several ATP-dependent processes such as the uptake of excitotoxic neurotransmitters (Beal, 1998; Trushina and McMurray, 2007). Such neuronal insults can contribute to glutamate excito- toxicity, which has been implicated in the etiology of seizurerelated disorders (Patel, 2002; Schipper, 2004b). In addition, excess $\mathrm{CO}$ production could cause dysfunction in synaptic plasticity and consequently lead to defects in cognitive development (Stevens and Wang, 1993; Zhuo et al., 1993). Similarly, the increased ERO1 $\alpha$ expression identified in Tsc-deficient neurons could potentially exacerbate neuronal function by enhancing ROS production (Harding et al., 2003; Marciniak et al., 2004). Therefore, the combination of ER and oxidative stress detected in Tsc-deficient neurons may contribute not only to epilepsy but also to neurodevelopmental disabilities in TSC patients.

\section{TSC1/TSC2 as key regulators of cellular stress responses}

Here we demonstrate a dynamic regulation of TSC1/TSC2 complex activity downstream of the PI3K/Akt pathway in cells under ER stress. We found that, under short exposure to ER stress, both Akt and mTOR are active, whereas the TSC1/TSC2 complex is inhibited. In contrast, under persistent ER stress, mTOR is inhibited in a Tsc-dependent manner. When cells undergo ER stress, the UPR is initially activated as part of a cellular protective mechanism to circumvent ER overload and reestablish proper ER function (Zhang and Kaufman, 2006). However, if ER stress persists, it results in cell death. Thus, cellular fate under ER stress is a balance between survival and apoptotic signals. Previous studies in cell lines from breast, lung, and prostate cancer have shown that the PI3K/Akt pathway can be differentially regulated to modulate cellular ER stress (Hu et al., 2004; Hosoi et al., 2007). We now show the TSC1/TSC2 plays a crucial role in the regulation of ER stress by PI3K/Akt. It is generally thought that the $\mathrm{PI} 3 \mathrm{~K} / \mathrm{Akt}$ pathway is regulated by extrinsic signals such as the activation of growth factor receptor tyrosine kinases. Our data indicate that cells under stress can intrinsically modulate the Akt/ TSC/mTOR pathway. Recent work has shown that neuronal injury, such as axotomy, can suppress mTOR and decrease protein synthesis (Park et al., 2008). Based on our findings, one possible mechanism underlying this effect may be through ER-stress mediated regulation of Akt and TSC. Exploring the cell-intrinsic upstream mechanisms regulating Akt/TSC/mTOR pathway will be important in understanding the biology of cellular stress and TSC disease. This has implications not only for TSC but also for the spectrum of neurological disorders in which either genetic mutations or environmental insults perturb ER function.

\section{References}

Barañano DE, Snyder SH (2001) Neural roles for heme oxygenase: contrasts to nitric oxide synthase. Proc Natl Acad Sci U S A 98:10996-11002.

Baybis M, Yu J, Lee A, Golden JA, Weiner H, McKhann G 2nd, Aronica E, Crino PB (2004) mTOR cascade activation distinguishes tubers from focal cortical dysplasia. Ann Neurol 56:478-487.

Beal MF (1998) Mitochondrial dysfunction in neurodegenerative diseases. Biochim Biophys Acta 1366:211-223.

Bertolotti A, Zhang Y, Hendershot LM, Harding HP, Ron D (2000) Dynamic interaction of $\mathrm{BiP}$ and ER stress transducers in the unfoldedprotein response. Nat Cell Biol 2:326-332.

Choi YJ, Di Nardo A, Kramvis I, Meikle L, Kwiatkowski DJ, Sahin M, He X (2008) Tuberous sclerosis complex proteins control axon formation. Genes Dev 22:2485-2495.

Crino PB, Nathanson KL, Henske EP (2006) The tuberous sclerosis complex. N Engl J Med 355:1345-1356.

Dorner AJ, Wasley LC, Kaufman RJ (1992) Overexpression of GRP78 mitigates stress induction of glucose regulated proteins and blocks secretion of selective proteins in Chinese hamster ovary cells. EMBO J 11:1563-1571.

Ehninger D, Han S, Shilyansky C, Zhou Y, Li W, Kwiatkowski DJ, Ramesh V, Silva AJ (2008) Reversal of learning deficits in a Tsc2 $+/-$ mouse model of tuberous sclerosis. Nat Med 14:843-848. 
Fawcett TW, Martindale JL, Guyton KZ, Hai T, Holbrook NJ (1999) Complexes containing activating transcription factor (ATF)/cAMPresponsive-element-binding protein (CREB) interact with the CCAAT/ enhancer-binding protein (C/EBP)-ATF composite site to regulate Gadd153 expression during the stress response. Biochem J 339:135-141.

Ferri KF, Kroemer G (2001) Organelle-specific initiation of cell death pathways. Nat Cell Biol 3:E255-E263.

Finlay GA, Thannickal VJ, Fanburg BL, Kwiatkowski DJ (2005) Plateletderived growth factor-induced p42/44 mitogen-activated protein kinase activation and cellular growth is mediated by reactive oxygen species in the absence of TSC2/tuberin. Cancer Res 65:10881-10890.

Flavell SW, Cowan CW, Kim TK, Greer PL, Lin Y, Paradis S, Griffith EC, Hu LS, Chen C, Greenberg ME (2006) Activity-dependent regulation of MEF2 transcription factors suppresses excitatory synapse number. Science 311:1008-1012.

Harding HP, Novoa I, Zhang Y, Zeng H, Wek R, Schapira M, Ron D (2000) Regulated translation initiation controls stress-induced gene expression in mammalian cells. Mol Cell 6:1099-1108.

Harding HP, Zhang Y, Zeng H, Novoa I, Lu PD, Calfon M, Sadri N, Yun C, Popko B, Paules R, Stojdl DF, Bell JC, Hettmann T, Leiden JM, Ron D (2003) An integrated stress response regulates amino acid metabolism and resistance to oxidative stress. Mol Cell 11:619-633.

Haynes CM, Titus EA, Cooper AA (2004) Degradation of misfolded proteins prevents ER-derived oxidative stress and cell death. Mol Cell 15:767-776

Hirose S (2006) A new paradigm of channelopathy in epilepsy syndromes: intracellular trafficking abnormality of channel molecules. Epilepsy Res 70 [Suppl 1]:S206-S217.

Hosoi T, Hyoda K, Okuma Y, Nomura Y, Ozawa K (2007) Akt up- and down-regulation in response to endoplasmic reticulum stress. Brain Res 1152:27-31.

Hu P, Han Z, Couvillon AD, Exton JH (2004) Critical role of endogenous Akt/IAPs and MEK1/ERK pathways in counteracting endoplasmic reticulum stress-induced cell death. J Biol Chem 279:49420-49429.

Inoki K, Li Y, Zhu T, Wu J, Guan KL (2002) TSC2 is phosphorylated and inhibited by Akt and suppresses mTOR signalling. Nat Cell Biol 4:648-657.

Kaufman RJ (2002) Orchestrating the unfolded protein response in health and disease. J Clin Invest 110:1389-1398.

Kim DY, Won SJ, Gwag BJ (2002) Analysis of mitochondrial free radical generation in animal models of neuronal disease. Free Radic Biol Med 33:715-723.

Koumenis C (2006) ER stress, hypoxia tolerance and tumor progression. Curr Mol Med 6:55-69.

Kwiatkowski DJ, Manning BD (2005) Tuberous sclerosis: a GAP at the crossroads of multiple signaling pathways. Hum Mol Genet 14 [Suppl 2]:R251-R258.

Lee K, Tirasophon W, Shen X, Michalak M, Prywes R, Okada T, Yoshida H, Mori K, Kaufman RJ (2002) IRE1-mediated unconventional mRNA splicing and S2P-mediated ATF6 cleavage merge to regulate XBP1 in signaling the unfolded protein response. Genes Dev 16:452-466.

Li M, Baumeister P, Roy B, Phan T, Foti D, Luo S, Lee AS (2000) ATF6 as a transcription activator of the endoplasmic reticulum stress element: thapsigargin stress-induced changes and synergistic interactions with NF-Y and YY1. Mol Cell Biol 20:5096-5106.

Liu CY, Schröder M, Kaufman RJ (2000) Ligand-independent dimerization activates the stress response kinases IRE1 and PERK in the lumen of the endoplasmic reticulum. J Biol Chem 275:24881-24885.

Liu CY, Xu Z, Kaufman RJ (2003) Structure and intermolecular interactions of the luminal dimerization domain of human IRElalpha. J Biol Chem 278:17680-17687.

Lurton D, Yacubian EM, Sanabria EG, Silva AV, Vianna R, Garzon E, Sakamoto A, Spreafico R, Cavalheiro EA (2002) Immunohistochemical study of six cases of Taylor's type focal cortical dysplasia: correlation with electroclinical data. Epilepsia 43 [Suppl 5]:217-219.

Ma Y, Brewer JW, Diehl JA, Hendershot LM (2002) Two distinct stress signaling pathways converge upon the CHOP promoter during the mammalian unfolded protein response. J Mol Biol 318:1351-1365.

Manning BD, Tee AR, Logsdon MN, Blenis J, Cantley LC (2002) Identification of the tuberous sclerosis complex-2 tumor suppressor gene product tuberin as a target of the phosphoinositide 3-kinase/akt pathway. Mol Cell 10:151-162.
Marciniak SJ, Yun CY, Oyadomari S, Novoa I, Zhang Y, Jungreis R, Nagata K, Harding HP, Ron D (2004) CHOP induces death by promoting protein synthesis and oxidation in the stressed endoplasmic reticulum. Genes Dev 18:3066-3077.

McCullough KD, Martindale JL, Klotz LO, Aw TY, Holbrook NJ (2001) Gadd153 sensitizes cells to endoplasmic reticulum stress by downregulating $\mathrm{Bcl} 2$ and perturbing the cellular redox state. Mol Cell Biol 21:1249-1259.

Meikle L, Talos DM, Onda H, Pollizzi K, Rotenberg A, Sahin M, Jensen FE, Kwiatkowski DJ (2007) A mouse model of tuberous sclerosis: neuronal loss of Tscl causes dysplastic and ectopic neurons, reduced myelination, seizure activity, and limited survival. J Neurosci 27:5546-5558.

Meikle L, Pollizzi K, Egnor A, Kramvis I, Lane H, Sahin M, Kwiatkowski DJ (2008) Response of a neuronal model of tuberous sclerosis to mammalian target of rapamycin (mTOR) inhibitors: effects on mTORC1 and Akt signaling lead to improved survival and function. J Neurosci 28:5422-5432.

Mori K (2000) Tripartite management of unfolded proteins in the endoplasmic reticulum. Cell 101:451-454.

Mostoslavsky G, Kotton DN, Fabian AJ, Gray JT, Lee JS, Mulligan RC (2005) Efficiency of transduction of highly purified murine hematopoietic stem cells by lentiviral and oncoretroviral vectors under conditions of minimal in vitro manipulation. Mol Ther 11:932-940.

Oyadomari S, Mori M (2004) Roles of CHOP/GADD153 in endoplasmic reticulum stress. Cell Death Differ 11:381-389.

Ozcan U, Ozcan L, Yilmaz E, Düvel K, Sahin M, Manning BD, Hotamisligil GS (2008) Loss of the tuberous sclerosis complex tumor suppressors triggers the unfolded protein response to regulate insulin signaling and apoptosis. Mol Cell 29:541-551.

Park KK, Liu K, Hu Y, Smith PD, Wang C, Cai B, Xu B, Connolly L, Kramvis I, Sahin M, He Z (2008) Promoting axon regeneration in the adult CNS by modulation of the PTEN/mTOR pathway. Science 322:963-966.

Patel M, Day BJ, Crapo JD, Fridovich I, McNamara JO (1996) Requirement for superoxide in excitotoxic cell death. Neuron 16:345-355.

Patel MN (2002) Oxidative stress, mitochondrial dysfunction, and epilepsy. Free Radic Res 36:1139-1146.

Potter CJ, Pedraza LG, Xu T (2002) Akt regulates growth by directly phosphorylating Tsc2. Nat Cell Biol 4:658-665.

Rao RV, Hermel E, Castro-Obregon S, del Rio G, Ellerby LM, Ellerby HM, Bredesen DE (2001) Coupling endoplasmic reticulum stress to the cell death program. Mechanism of caspase activation. J Biol Chem 276:33869-33874.

Reynolds A, Laurie C, Mosley RL, Gendelman HE (2007) Oxidative stress and the pathogenesis of neurodegenerative disorders. Int Rev Neurobiol 82:297-325.

Ron D, Walter P (2007) Signal integration in the endoplasmic reticulum unfolded protein response. Nat Rev Mol Cell Biol 8:519-529.

Rutkowski DT, Kaufman RJ (2004) A trip to the ER: coping with stress. Trends Cell Biol 14:20-28.

Ryter SW, Tyrrell RM (2000) The heme synthesis and degradation pathways: role in oxidant sensitivity. Heme oxygenase has both pro- and antioxidant properties. Free Radic Biol Med 28:289-309.

Sahin M, Greer PL, Lin MZ, Poucher H, Eberhart J, Schmidt S, Wright TM, Shamah SM, O'connell S, Cowan CW, Hu L, Goldberg JL, Debant A, Corfas G, Krull CE, Greenberg ME (2005) Eph-dependent tyrosine phosphorylation of ephexin 1 mediates growth cone collapse. Neuron 46:191-204.

Schipper HM (2004a) Heme oxygenase-1: transducer of pathological brain iron sequestration under oxidative stress. Ann N Y Acad Sci 1012:84-93.

Schipper HM (2004b) Heme oxygenase expression in human central nervous system disorders. Free Radic Biol Med 37:1995-2011.

Sevier CS, Kaiser CA (2008) Erol and redox homeostasis in the endoplasmic reticulum. Biochim Biophys Acta 1783:549-556.

Sokka AL, Putkonen N, Mudo G, Pryazhnikov E, Reijonen S, Khiroug L, Belluardo N, Lindholm D, Korhonen L (2007) Endoplasmic reticulum stress inhibition protects against excitotoxic neuronal injury in the rat brain. J Neurosci 27:901-908.

Stevens CF, Wang Y (1993) Reversal of long-term potentiation by inhibitors of haem oxygenase. Nature 364:147-149.

Takahashi T, Morita K, Akagi R, Sassa S (2004) Heme oxygenase-1: a novel 
therapeutic target in oxidative tissue injuries. Curr Med Chem 11:1545-1561.

Tavazoie SF, Alvarez VA, Ridenour DA, Kwiatkowski DJ, Sabatini BL (2005) Regulation of neuronal morphology and function by the tumor suppressors Tsc1 and Tsc2. Nat Neurosci 8:1727-1734.

Trushina E, McMurray CT (2007) Oxidative stress and mitochondrial dysfunction in neurodegenerative diseases. Neuroscience 145: 1233-1248.

Urano F, Wang X, Bertolotti A, Zhang Y, Chung P, Harding HP, Ron D (2000) Coupling of stress in the ER to activation of JNK protein kinases by transmembrane protein kinase IRE1. Science 287:664-666.

Verkhratsky A, Petersen OH (2002) The endoplasmic reticulum as an integrating signalling organelle: from neuronal signalling to neuronal death. Eur J Pharmacol 447:141-154.

Wang XZ, Kuroda M, Sok J, Batchvarova N, Kimmel R, Chung P, Zinszner H, Ron D (1998) Identification of novel stress-induced genes downstream of chop. EMBO J 17:3619-3630.

Yamamoto A, Murphy N, Schindler CK, So NK, Stohr S, Taki W, Prehn JH, Henshall DC (2006) Endoplasmic reticulum stress and apoptosis signal- ing in human temporal lobe epilepsy. J Neuropathol Exp Neurol 65:217-225.

Yokouchi M, Hiramatsu N, Hayakawa K, Okamura M, Du S, Kasai A, Takano Y, Shitamura A, Shimada T, Yao J, Kitamura M (2008) Involvement of selective reactive oxygen species upstream of proapoptotic branches of unfolded protein response. J Biol Chem 283:4252-4260.

Zeng LH, Xu L, Gutmann DH, Wong M (2008) Rapamycin prevents epilepsy in a mouse model of tuberous sclerosis complex. Ann Neurol 63:444-453.

Zhang HH, Lipovsky AI, Dibble CC, Sahin M, Manning BD (2006) S6K1 regulates GSK3 under conditions of mTOR-dependent feedback inhibition of Akt. Mol Cell 24:185-197.

Zhang K, Kaufman RJ (2006) The unfolded protein response: a stress signaling pathway critical for health and disease. Neurology 66:S102-S109.

Zhuo M, Small SA, Kandel ER, Hawkins RD (1993) Nitric oxide and carbon monoxide produce activity-dependent long-term synaptic enhancement in hippocampus. Science 260:1946-1950. 